\title{
Systematic review and meta-analysis of clinical effectiveness of self-management interventions in Parkinson's disease
}

\author{
Jennifer S. Pigott ${ }^{1}$, Edward J. Kane ${ }^{2}$, Gareth Ambler ${ }^{3}$, Kate Walters ${ }^{4}$ and Anette Schrag ${ }^{1,5^{*}}$
}

\begin{abstract}
Background: Parkinson's disease is a complex neurodegenerative condition with significant impact on quality of life (QoL), wellbeing and function. The objective of this review is to evaluate the clinical effectiveness of self-management interventions for people with Parkinson's disease, taking a broad view of self-management and considering effects on QoL, wellbeing and function.

Methods: Systematic searches of four databases (MEDLINE, Embase, PsycINFO, Web of Science) were conducted for studies evaluating self-management interventions for people with Parkinson's disease published up to 16th November 2020. Original quantitative studies of adults with idiopathic Parkinson's disease were included, whilst studies of atypical Parkinsonism were excluded. Full-text articles were independently assessed by two reviewers, with data extracted by one reviewer and reliability checked by a second reviewer, then synthesised through a narrative approach and, for sufficiently similar studies, a meta-analysis of effect size was conducted (using a random-effects meta-analysis with restricted maximum likelihood method pooled estimate). Interventions were subdivided into selfmanagement components according to PRISMS Taxonomy. Risk of bias was examined with the Cochrane Risk of Bias 2 (RoB2) tool or ROBIN-I tool as appropriate.
\end{abstract}

Results: Thirty-six studies were included, evaluating a diverse array of interventions and encompassing a range of study designs (RCT $n=19$; non-randomised $C T n=$ five; within subject pre- and post-intervention comparisons $n=12$ ). A total of 2884 participants were assessed in studies across ten countries, with greatest output from North America (14 studies) and UK (six studies). Risk of bias was moderate to high for the majority of studies, mostly due to lack of participant blinding, which is not often practical for interventions of this nature. Only four studies reported statistically significant improvements in QoL, wellbeing or functional outcomes for the intervention compared to controls. These interventions were group-based self-management education and training programmes, either alone, combined with multi-disciplinary rehabilitation, or combined with Cognitive Behaviour Therapy; and a self-guided community-based exercise programme. Four of the RCTs evaluated sufficiently similar interventions and outcomes for meta-analysis: these were studies of self-management education and training programmes evaluating QoL ( $n=478)$. Meta-analysis demonstrated no significant difference between the self-management and the control groups with a standardised mean difference (Hedges $g$ ) of $-0.17(-0.56,0.21) p=0.38$. By the GRADE approach, the quality of this evidence was deemed "very low" and the effect of the intervention is therefore uncertain.

\footnotetext{
*Correspondence: a.schrag@ucl.ac.uk

${ }^{1}$ Queen Square Institute of Neurology, University College London,

London, UK

Full list of author information is available at the end of the article
} original author(s) and the source, provide a link to the Creative Commons licence, and indicate if changes were made. The images or other third party material in this article are included in the article's Creative Commons licence, unless indicated otherwise in a credit line to the material. If material is not included in the article's Creative Commons licence and your intended use is not permitted by statutory regulation or exceeds the permitted use, you will need to obtain permission directly from the copyright holder. To view a copy of this licence, visit http://creativecommons.org/licenses/by/4.0/. The Creative Commons Public Domain Dedication waiver (http://creativeco $\mathrm{mmons}$.org/publicdomain/zero/1.0/) applies to the data made available in this article, unless otherwise stated in a credit line to the data. 
Components more frequently observed in effective interventions, as per PRISMS taxonomy analysis, were: information about resources; training or rehearsing psychological strategies; social support; and lifestyle advice and support. The applicability of these findings is weakened by the ambiguous and at times overlapping nature of self-management components.

Conclusion: Approaches and outcomes to self-management interventions in Parkinson's disease are heterogenous. There are insufficient high quality RCTs in this field to show effectiveness of self-management interventions in Parkinson's disease. Whilst it is not possible to draw conclusions on specific intervention components that convey effectiveness, there are promising findings from some studies, which could be targeted in future evaluations.

Keywords: Parkinson's disease, Long-term health conditions, Neurodegenerative disease, Self-management, Selfcare, Quality of life, Wellbeing, Activities of daily living, Functioning, Systematic review

\section{GRADE summary of findings}

\begin{tabular}{|c|c|c|c|c|}
\hline \multicolumn{5}{|c|}{ Self-Management for people with Parkinson's disease and their } \\
\hline \multicolumn{5}{|c|}{$\begin{array}{l}\text { Population: people with idiopathic Parkinson's disease and/or their } \\
\text { caregivers } \\
\text { Intervention: self-management } \\
\text { Comparison: control arm (usual care or information only) }\end{array}$} \\
\hline \multirow[t]{2}{*}{ Outcomes } & $\begin{array}{l}\text { Illustrative } \\
\text { Risks }\end{array}$ & omparative & $\begin{array}{l}\text { No. of par- } \\
\text { ticipants } \\
\text { (studies) }\end{array}$ & $\begin{array}{l}\text { Quality of } \\
\text { the evidence } \\
\text { (GRADE) }\end{array}$ \\
\hline & Usual Care & $\begin{array}{l}\text { Self-man- } \\
\text { agement }\end{array}$ & & \\
\hline $\begin{array}{l}\text { Quality of } \\
\text { Life PDQ39 } \\
\text { or custom } \\
\text { question- } \\
\text { naire } \\
\text { (follow-up } \\
\text { range } \\
3 \text { weeks- } \\
6 \text { months) }\end{array}$ & $\begin{array}{l}\text { See Com- } \\
\text { ment }^{*}\end{array}$ & $\begin{array}{l}\text { See Com- } \\
\text { ment }^{*}\end{array}$ & $478(4)$ & $\begin{array}{l}\oplus \bigcirc \bigcirc \bigcirc \\
\text { VERY LOW } \\
\text { Due to } \\
\text { serious risk } \\
\text { of bias, incon- } \\
\text { sistency, and } \\
\text { imprecision. }\end{array}$ \\
\hline
\end{tabular}

For GRADE evidence profile, see Additional file 5

Note a further 32 studies are also discussed in this review, evaluating a range of clinical outcomes

\section{* Mean values are not presented since 3 trials reported values for PDQ-39 whereas the 4th reported values from a custom questionnaire. Furthermore, 3 trials reported post-randomisation values, and the 4th reported 'change' valuesIntroduction}

Parkinson's disease is a complex progressive neurological condition for which there is currently no cure. Its prevalence is rising [1], and increases with age [2]. Parkinson's disease is associated with a range of motor and non-motor features that affect quality of life [3], but clinical reviews to improve these features may not be frequent enough to address these. In the last few years, there has therefore been increasing interest in the use of self-management approaches for features of Parkinson's disease. Research in other long term conditions (LTCs) has provided evidence that supporting self-management can improve health and quality of life outcomes, and may decrease health care utilisation [4].

Core self-management skills include: problem solving, decision making, resource utilisation, forming of a patient/health care provider partnership, and taking action [5]. Self-management support interventions aim to develop these skills for people with LTCs. Key components of self-management support [6] have been defined through the PRISMS taxonomy, which comprises 14 components, e.g. "monitoring of condition with feedback" and "social support". As these differ between LTC, condition-specific self-management interventions have emerged, with evidence that effective interventions are multifaceted and tailored to the individual [7].

In Parkinson's disease, disease progression simultaneously increases illness demands and challenges an individual's physical and cognitive capacity to adapt to such demands. The heterogeneity of experience of Parkinson's disease makes a uniform approach difficult. However, recommendations for management exist based on evidence for improved outcomes for people with Parkinson's disease, including medication, non-pharmacological therapy and exercise recommendations [8]. Patient choices in day-to-day life influence these, and are therefore potential targets for self-management.

A previous review of self-management approaches in Parkinson's disease (2016) identified 18 interventions, 16 specifically for Parkinson's disease, although studies targeting a single outcome were excluded [9]. The interventions varied in structure, content, and targeted outcomes. Evidence to support self-management programmes for Parkinson's disease was found to be limited: Only 7 fulltext studies were included, and only 1 was a randomised controlled trial (RCT). Others were identified conference abstracts ( 5 presenting data, 3 only descriptions of interventions), reviews or protocol papers. $39 \%$ of the interventions included the three key self-management components of education, goal setting and problem 
solving. Effective active components of interventions could not be determined, but the authors speculated that potential factors impacting effectiveness may be: intervention factors, such as caregiver involvement and peer-interaction, participant factors such as stage and cognitive condition, and, in the future, use of technology.

As there has been a substantial increase in studies in this field since 2016, we conducted a new systematic review and meta-analysis, considering data also from more recent studies and taking a broader view of selfmanagement interventions, through wider inclusion criteria (see 2. Methods). This adds breadth to the range of interventions considered, reflective of the breadth of issues in Parkinson's disease. Whilst not excluding on the basis of outcome measure, we particularly focus on quality of life (QoL), wellbeing and functional outcome measures in this review as a patient-centred approach for patient-focussed interventions [10].

\section{Methods}

\section{Source of Data \& Search Strategy}

This review was conducted according to the Preferred Reporting Items for Systematic Reviews and Meta-analyses (PRISMA) guidelines [11, 12]. Small deviations from the guidelines have been described, along with rationale, in the relevant sections. The review protocol was registered on PROSPERO: CRD42019117183.

One reviewer conducted online searches in the following databases: MEDLINE, Embase, PsycINFO, Web of Science. They were searched from inception, initially to 31st October 2018 (EK), with an updated search on 16th November 2020 (JP). Searches were not restricted by date of publication. Forwards and backwards citation tracking of key articles to identify other relevant studies was conducted.

The search strategy involved a combination of Parkinson's disease terms; "Parkinson" OR Parkinson's Disease, AND self-management terms; Self-Management OR Self care. For the full search strategy see Additional file 1.

\section{Inclusion \& Exclusion Criteria}

The inclusion criteria are detailed in Table 1 using the PICOS format.

Whilst there is no agreed single definition of self-management, we used Barlow et al's definition: an "individual's ability to manage the symptoms, treatment, physical and psychological consequences and lifestyle changes inherent in living with a chronic condition" [15]. Interventions self-defining as 'self-management' were checked against this definition. Additionally, where the term 'selfmanagement' was not used, if the premise of the intervention was the individual managing their Parkinson's disease symptoms, treatments or consequences, or being taught to do so, then the intervention was included. As a result, in the context of Parkinson's disease, studies targeting self-management of specific clinical aspects, such as posture, and drooling, and those targeting self-management of specific treatments, such as exercises, were considered fulfilling the inclusion criteria.

\section{Study selection}

One reviewer (EK for initial search, JP for update) screened all titles and abstracts of the identified studies in accordance with the inclusion and exclusion criteria. For those deemed eligible from screening, full texts were obtained and reviewed independently by both reviewers (EK and JP). Any discrepancies were discussed and resolved through consultation with a third and fourth reviewer (AS and KW).

\section{Data extraction}

Data extraction was performed by one reviewer (JP) with a second reviewer (EK) conducting an independent reliability check. No discrepancies were identified. Data was extracted into a standardised form, including: lead author, publication date, country; population; study design; intervention type; sample size, age and stage of Parkinson's disease; results for primary outcomes, and for secondary outcome measures of quality of life (QoL), wellbeing and function (Activities of Daily Living) measures. Articles reporting on the same intervention with overlapping samples were each included for data extraction.

\section{Data synthesis}

Meta-analysis was undertaken for the studies using similar aims, interventions and outcomes. For the remainder, a narrative synthesis approach is taken. For meta-analysis, we estimated the standardised mean difference (Hedges g) and standard error from each study, then used random-effects meta-analysis with REML (restricted maximum likelihood) to estimate the pooled estimate. The $\mathrm{I}^{2}$ statistic was used to quantify heterogeneity. Statistical analyses were conducted using Stata 16.1.

\section{Quality}

The RCTs were examined for bias using the Cochrane Risk of Bias 2 (RoB2) tool [16]. This tool assesses several key areas of potential bias: randomisation methods; deviations from intended intervention; missing data; measurement of outcome; and selection of reported result. The non-randomized studies of interventions (NRSIs) were assessed using the ROBIN-I tool [17]. This tool assesses risk of bias due to confounding; selection bias; classification of the intervention; deviations from intended intervention; missing data; measurement of outcome; 


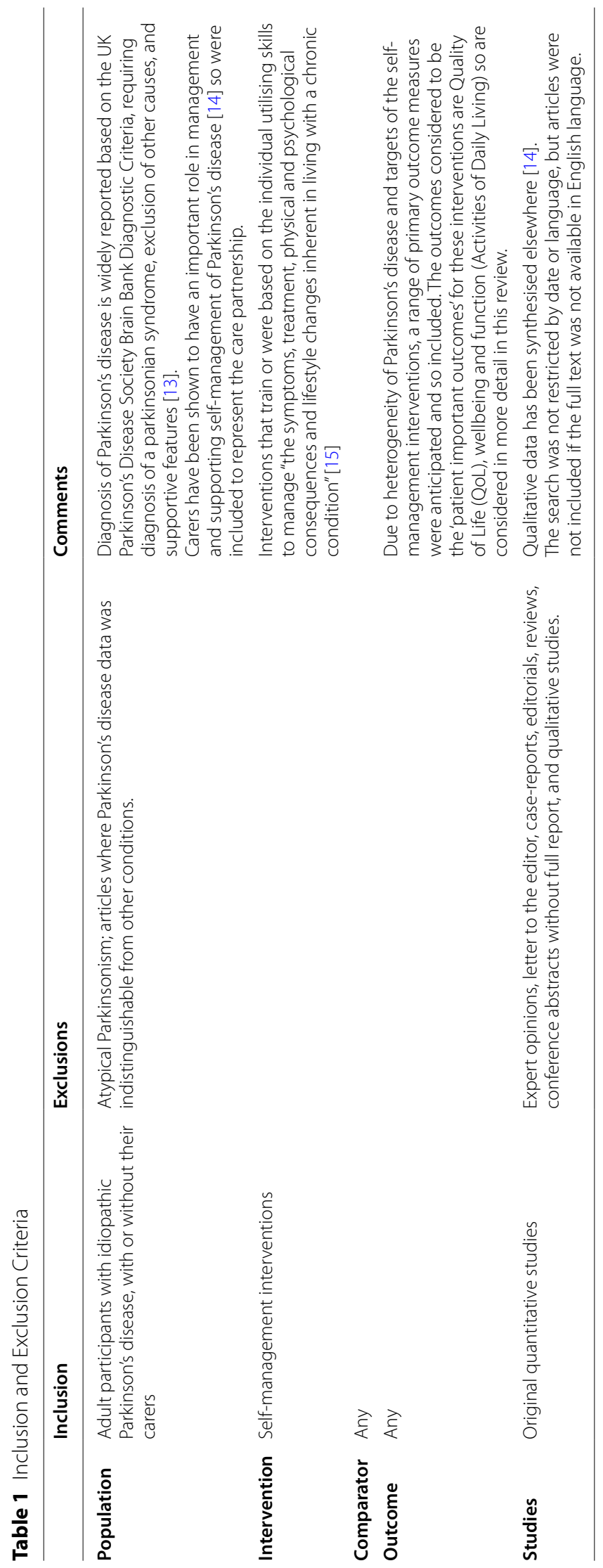


and selection of reported result. A 'Low' risk of bias on ROBIN-I for NRSI is considered to mean the study is comparable to a well-performed RCT with regard to the specific domain. 'Moderate' risk of bias is considered to mean the study is sound for a non-randomized study with regard to this domain but cannot be considered comparable to a well-performed RCT. For both, the risk of bias was assessed against the specific outcome. The GRADE approach was followed and uncertainty assessment performed for studies included in meta-analysis [18].

\section{Results}

\section{Study selection}

As shown in Fig. 1, the online databases search yielded a total of 1303 articles: 824 in the original search and a further 479 articles through the update. Eight additional articles were identified through citation screening. Removal of duplicates left 878 articles. Through screening of abstracts, 127 articles were found to be eligible for full text review, three of which were unavailable in English. By means of independent full review, both reviewers agreed on exclusion of 88 articles with reasons, leaving the inclusion of 36 articles in the final review. Reasons for exclusion were: nature of article or study design $(n=61)$; interventions were not self-management $(n=14)$; duplicates $(n=6)$; no Parkinson's disease specific data presented $(n=6)$; description of intervention without outcome measures $(n=1)$.

\section{Quality assessment}

The results of quality assessment are summarised in Table 2 (see Additional file 3 for full assessment results). Risk of Bias was moderate to high for almost all included studies. The main determinant for bias is the selfreported nature of the outcome measures combined with lack of participant blinding. This concern was almost universal as relates to the nature of these interventions - participants know whether or not they have received

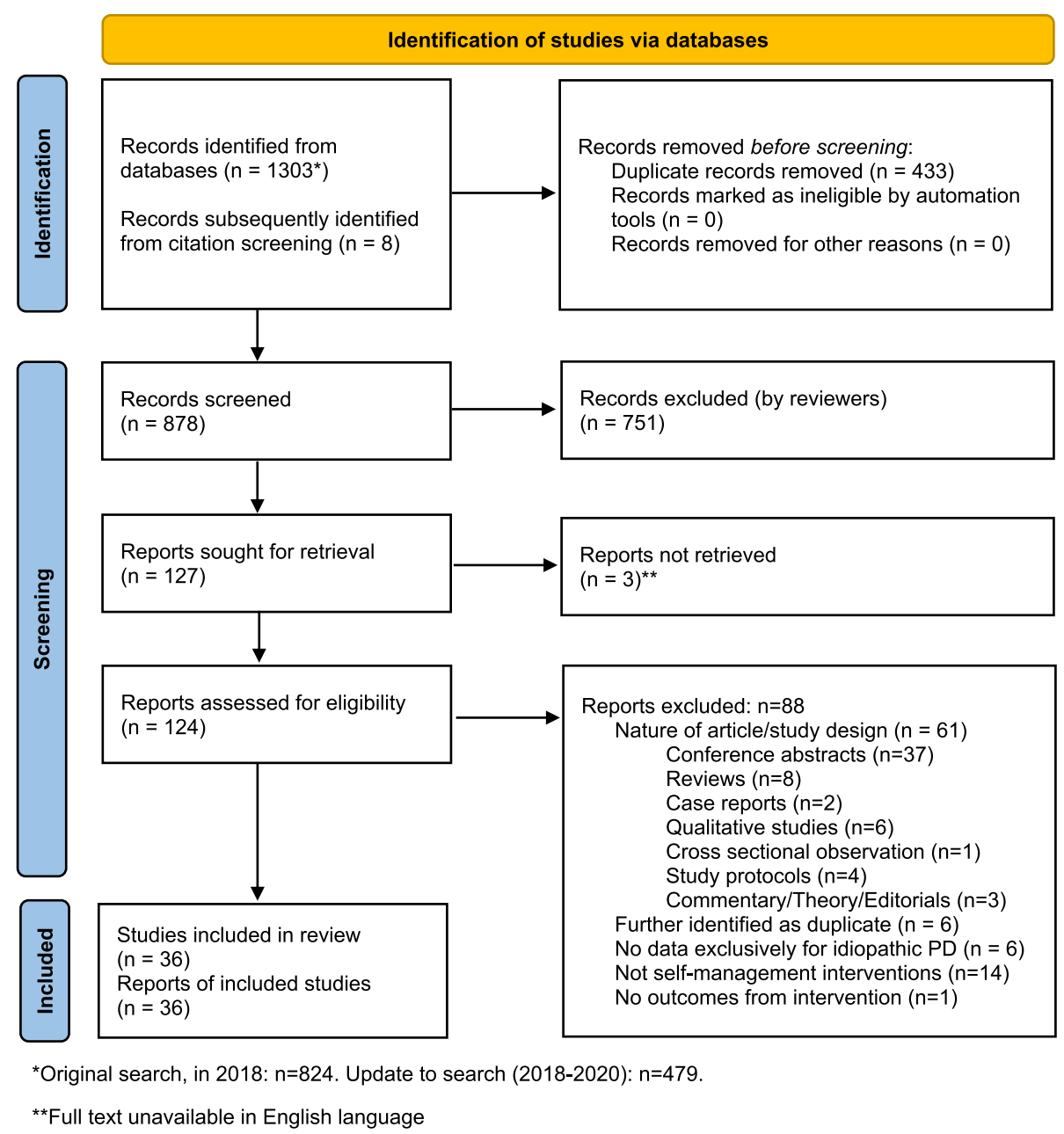

Fig. 1 PRISMA Flow Diagram 


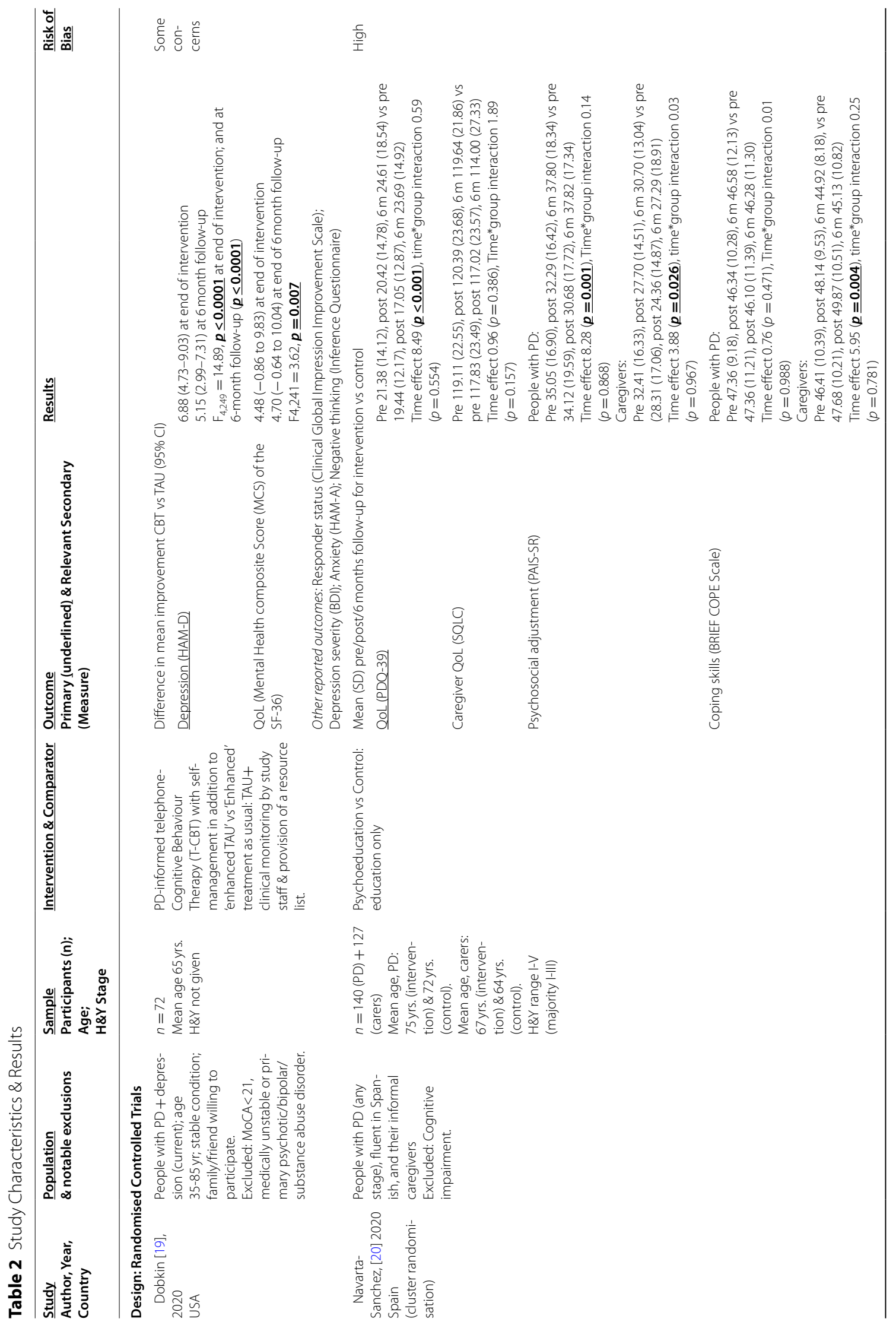




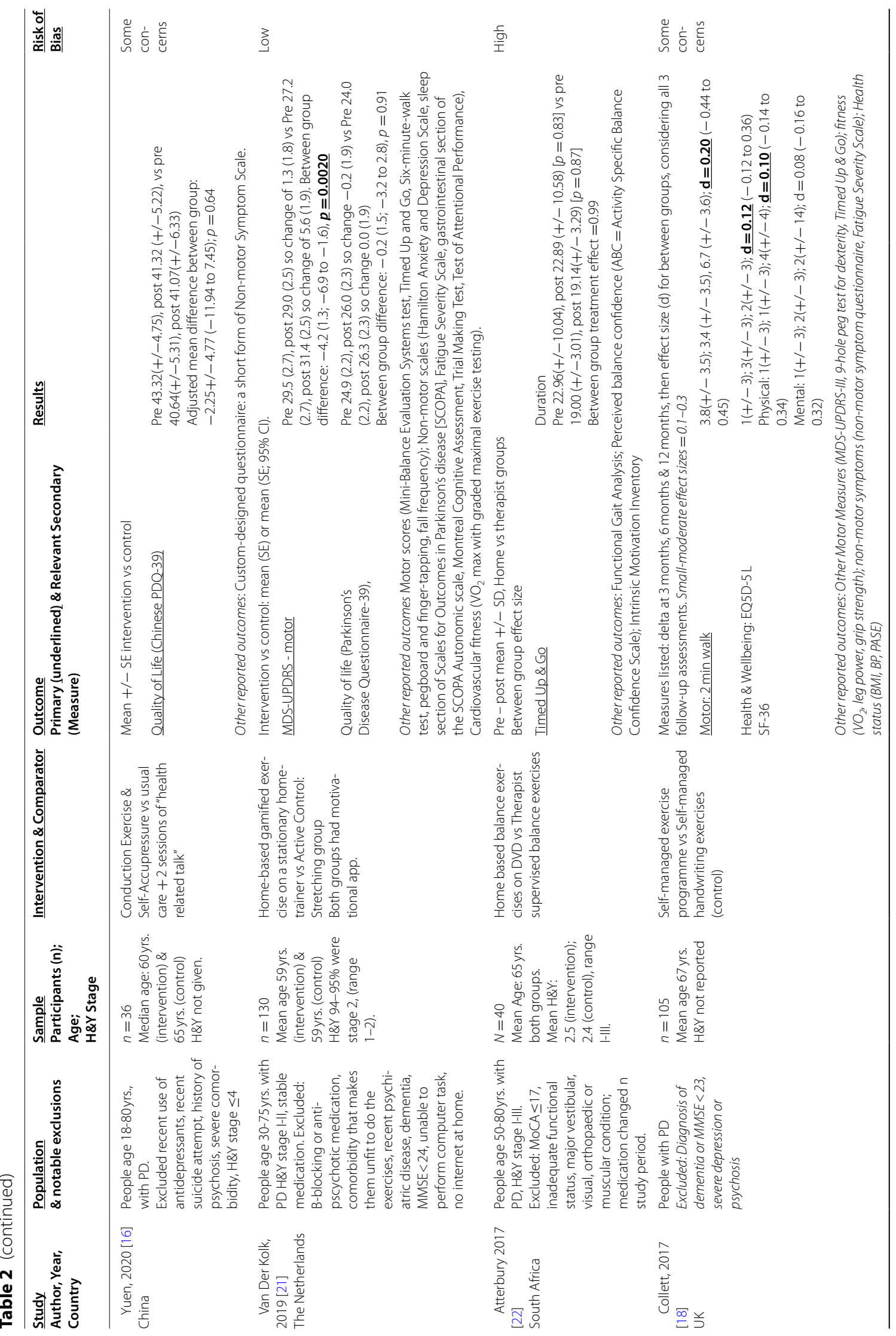




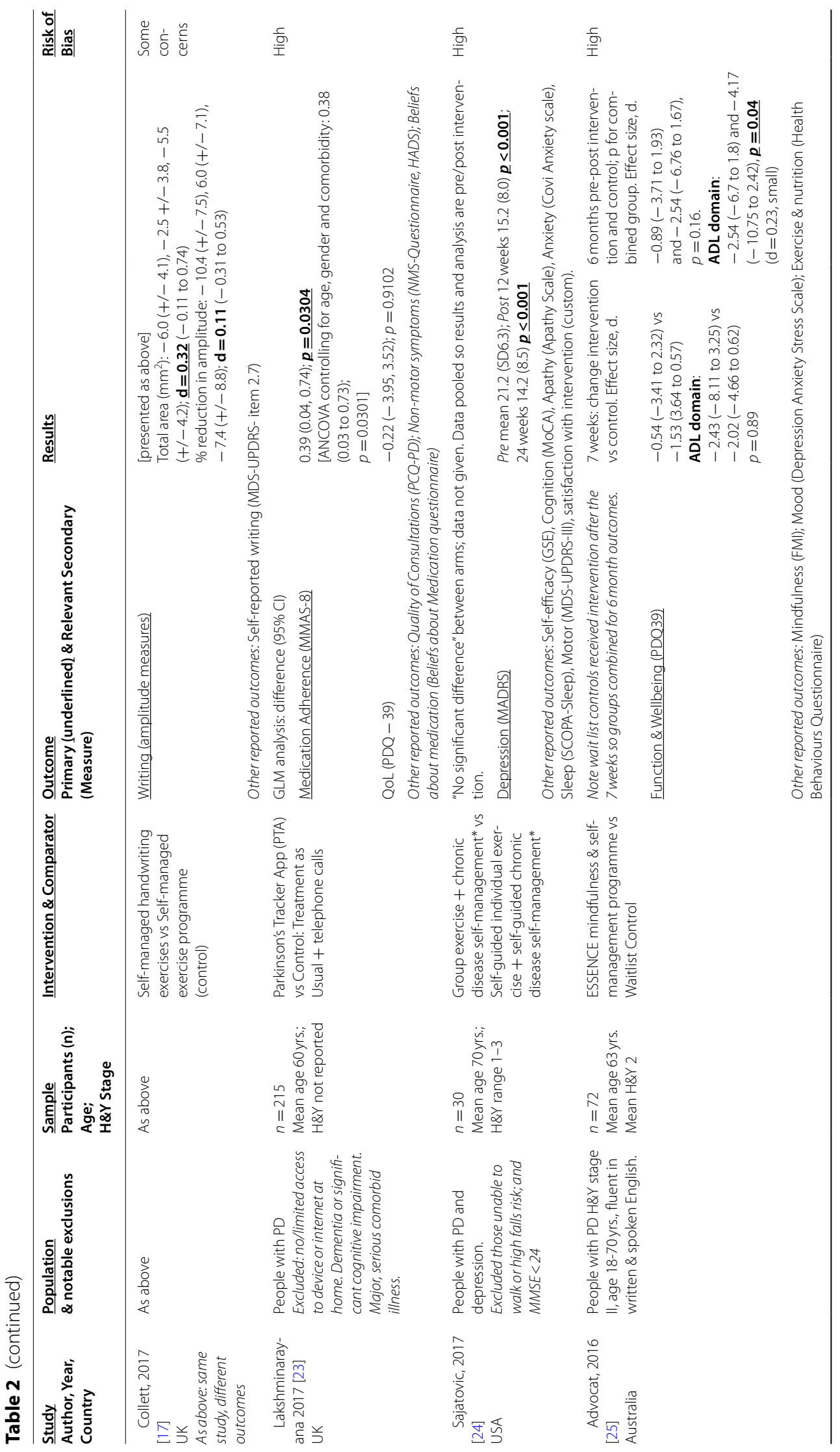




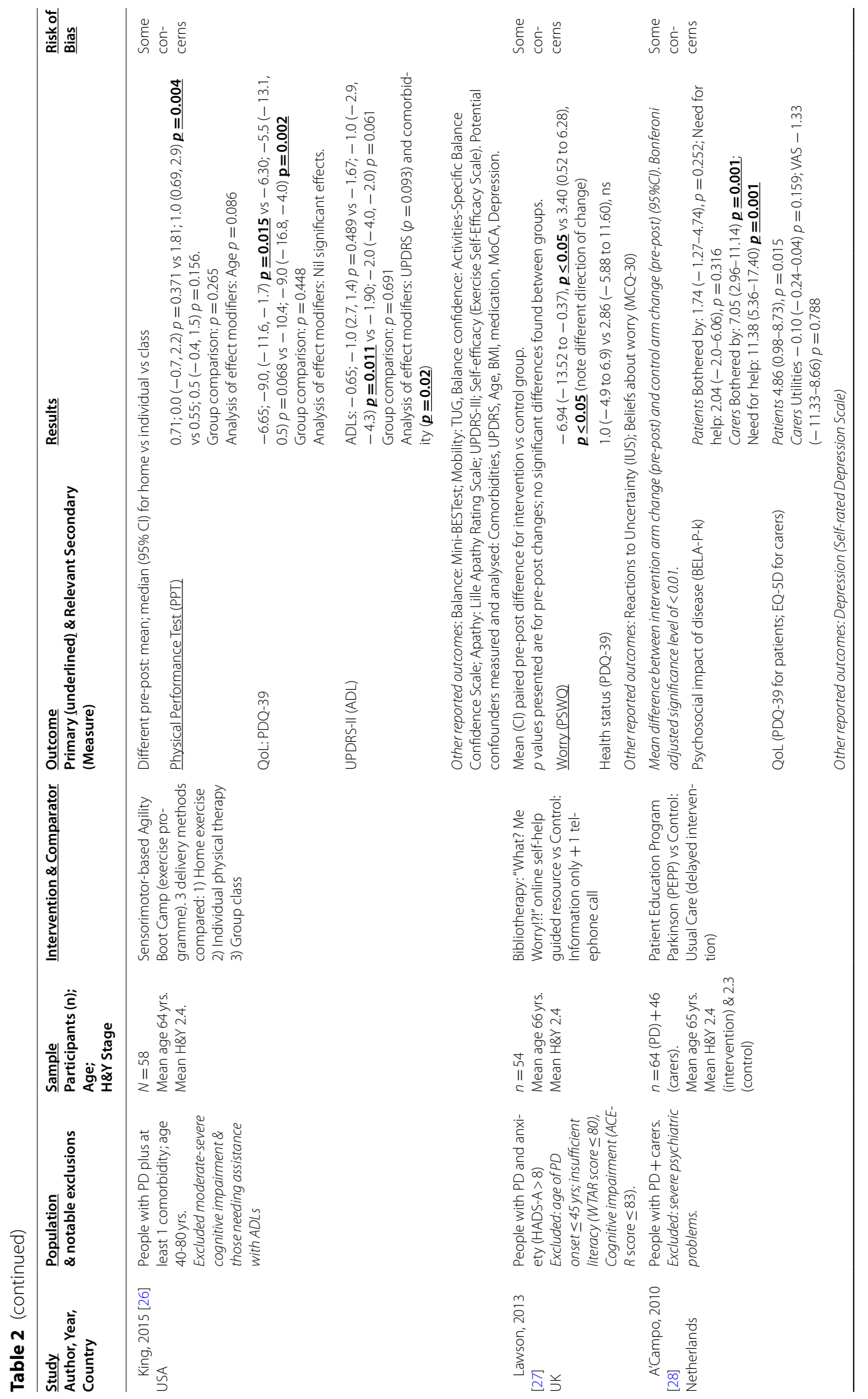




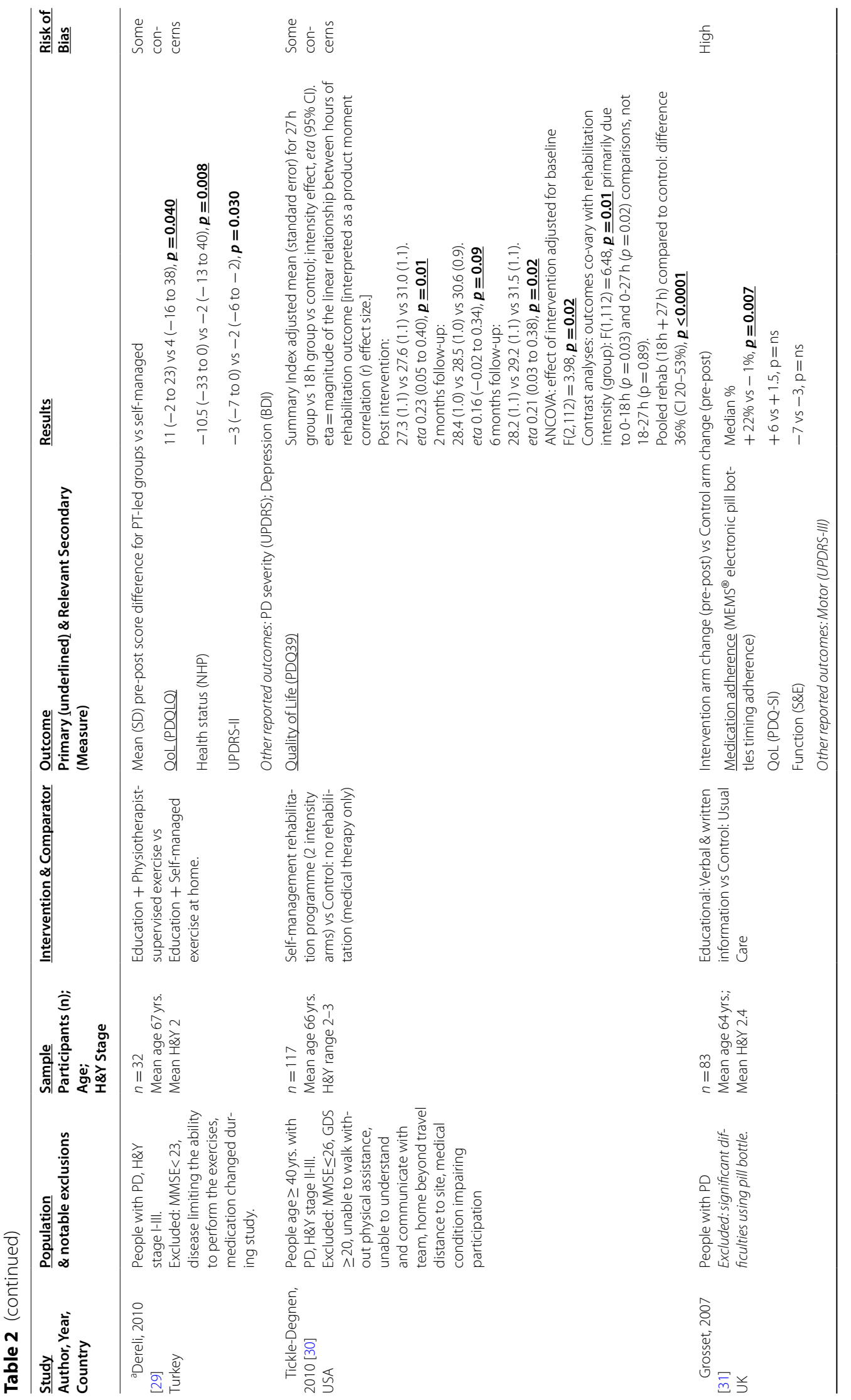




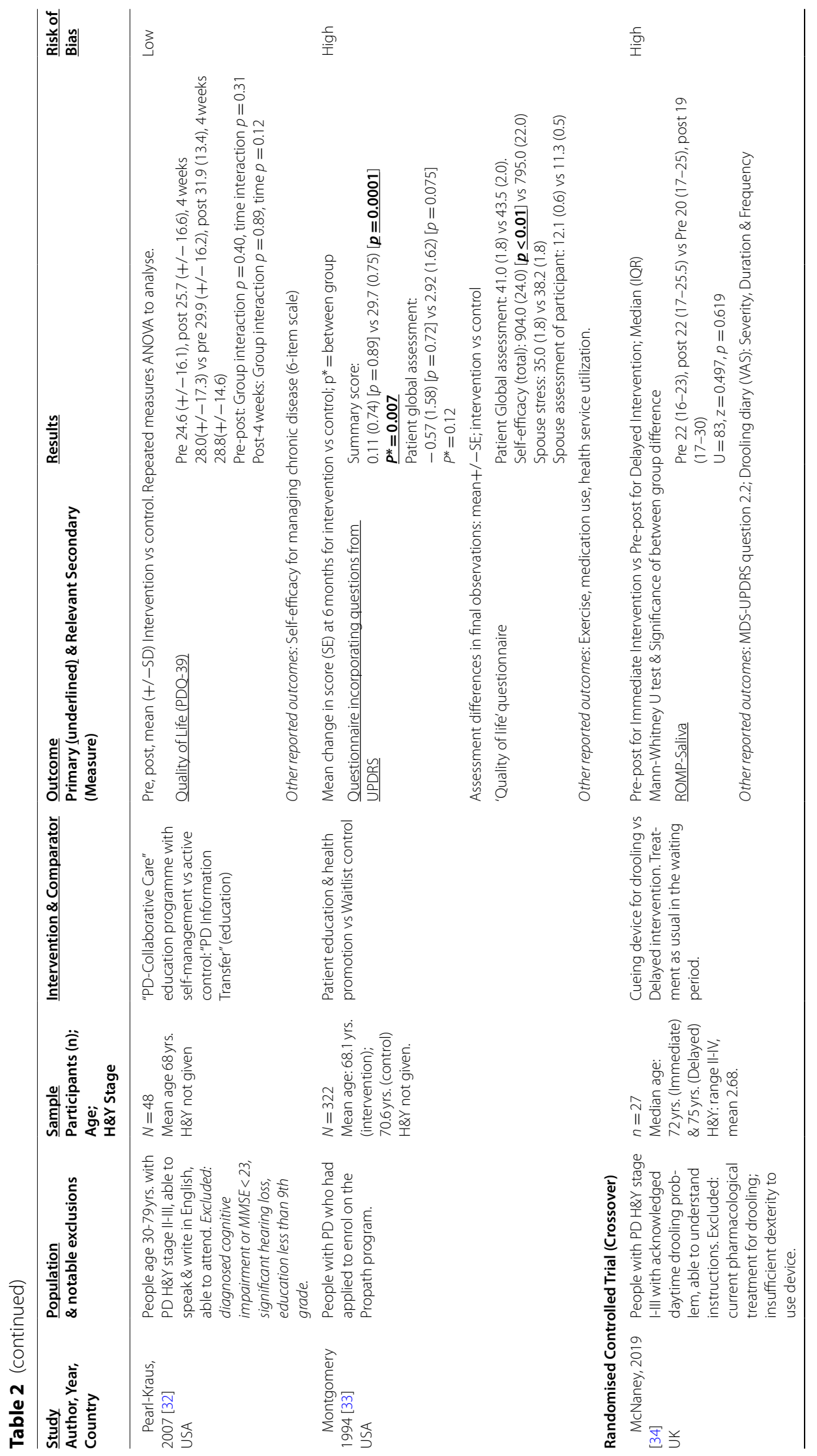




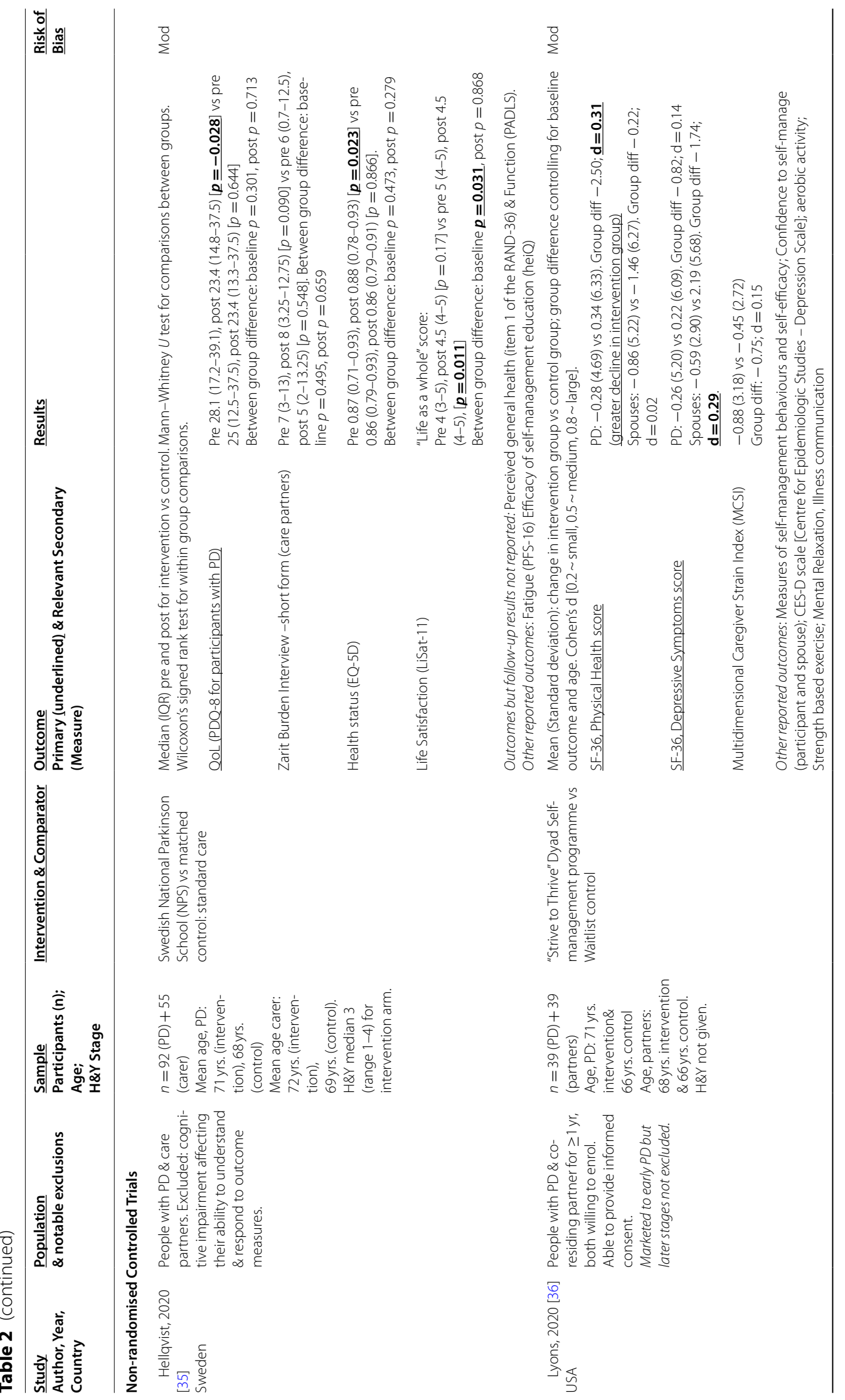




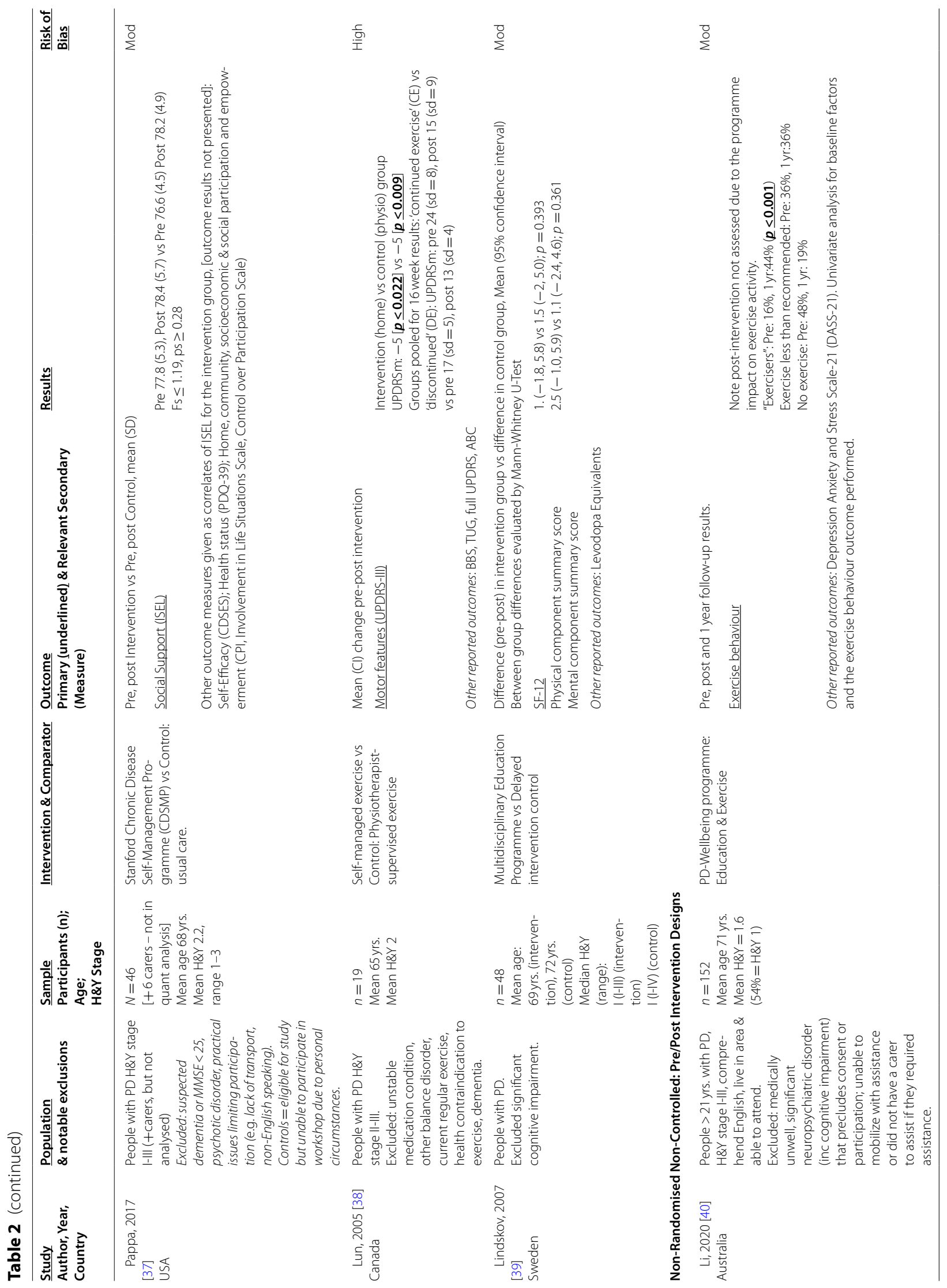




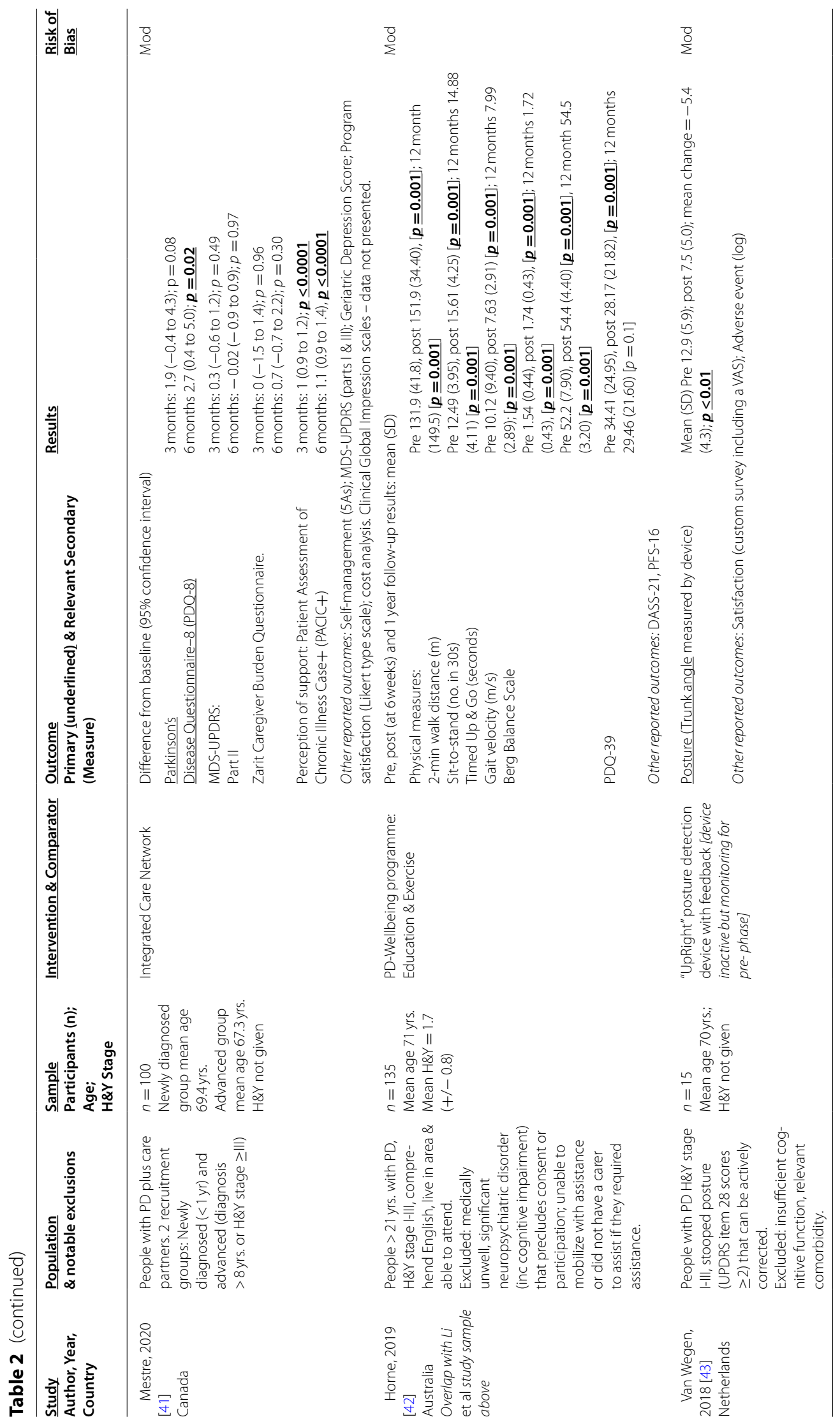




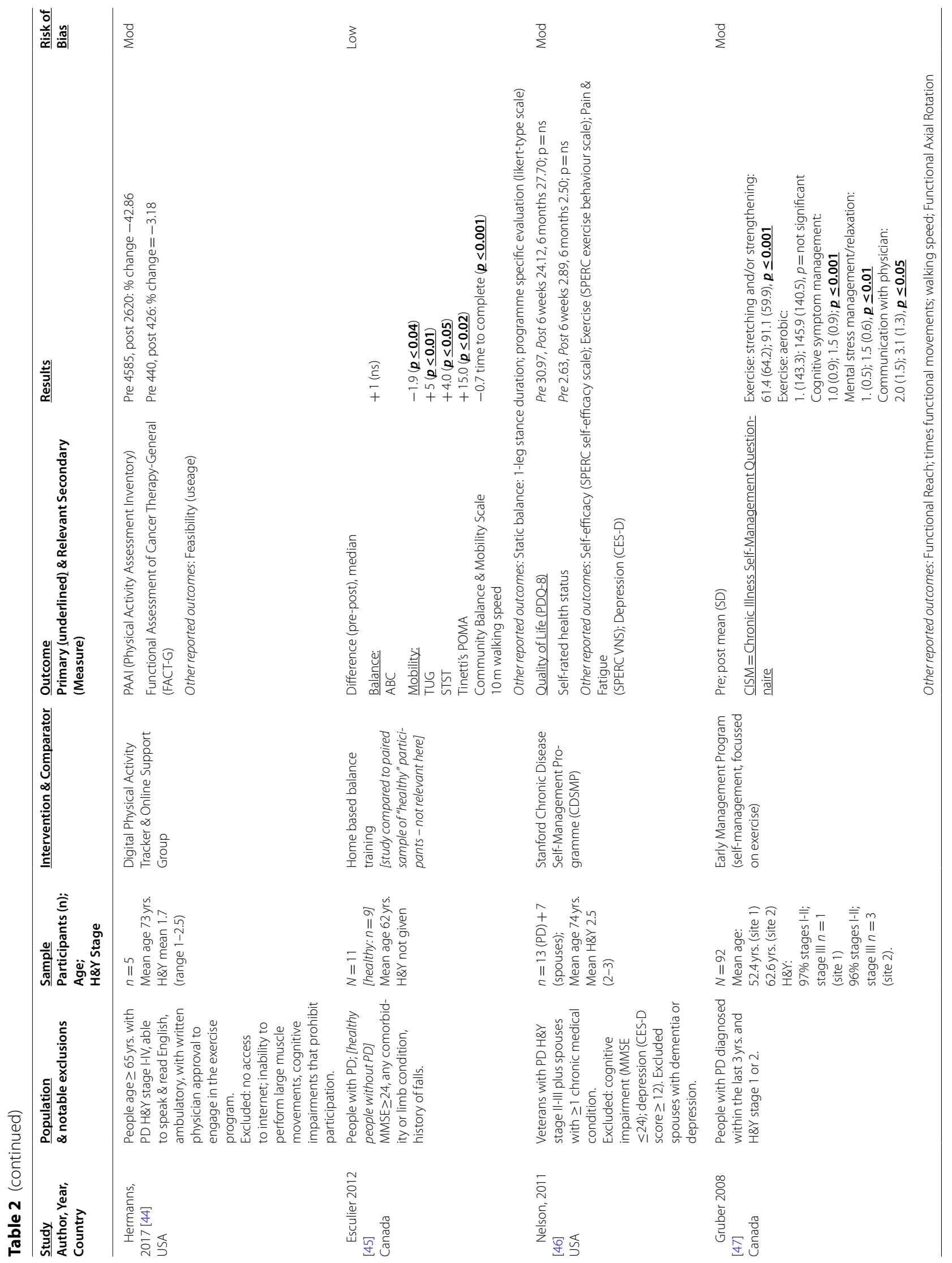




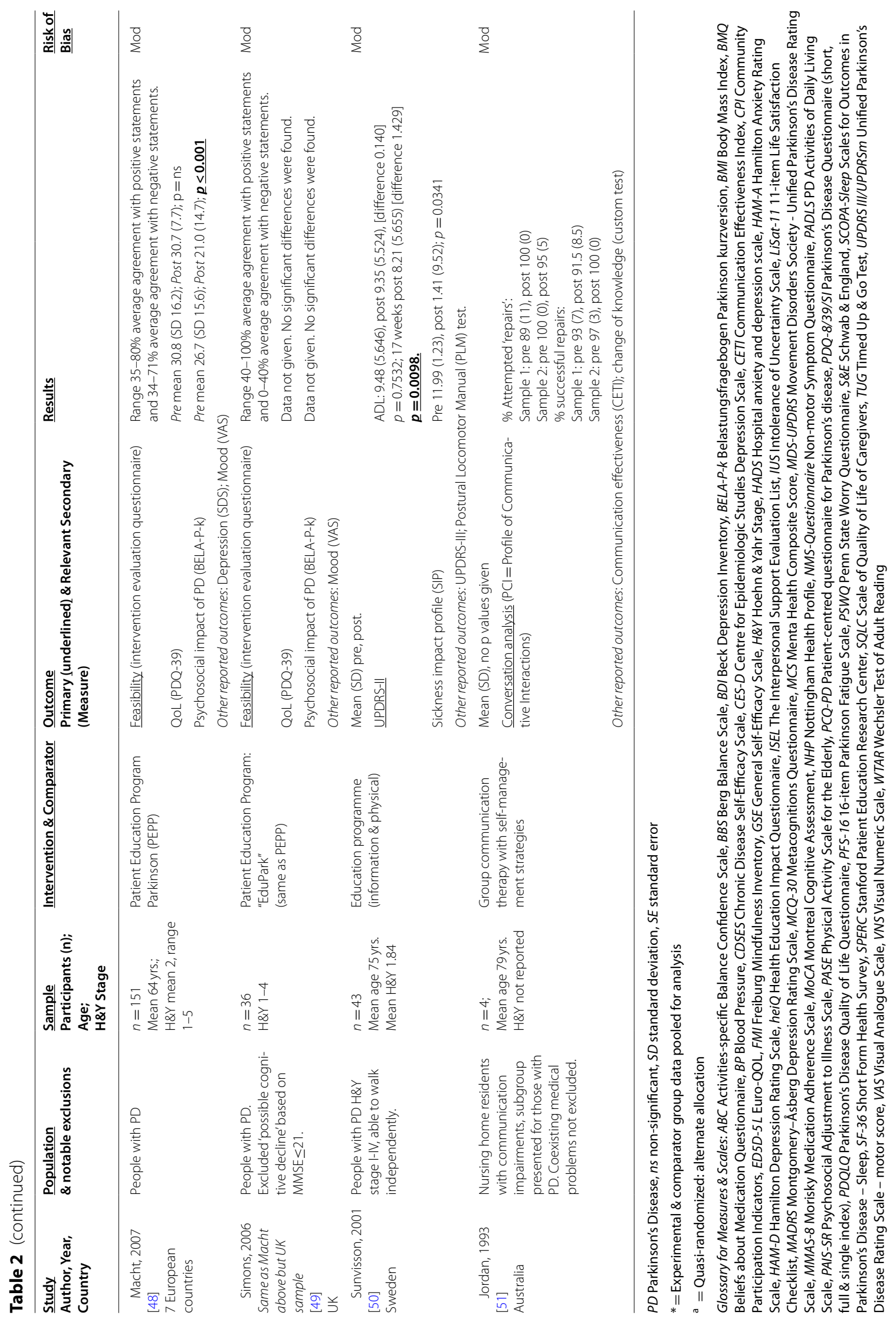


the intervention, and so lower risk of bias would not be possible to achieve. The only studies achieving low risk of bias used active controls to achieve participant blinding to allocation. Deviations from protocol were rare, but missing data due to participant drop-out was not uncommon.

Details of attrition were not clearly described for all studies. Attrition rates ranged from zero to $50 \%$. For controlled trials, the majority showed greater drop-out rates from intervention arms than control arms, with the exception of one study [49] where the control group drop-out rate was double that of the intervention group. This was thought to be due to disappointment of allocation to the control arm, an issue minimised in other studies through use of waitlist or active control arms.

\section{Characteristics of selected studies}

As summarized in Table 2, a total of 2884 participants, were assessed in studies across USA (10 studies), UK (6 studies), Canada (4 studies), Australia (4 studies), Netherlands (3 studies), Sweden (3 studies), Spain (1 study), Turkey (1 study), China (1 study), South Africa (1 study) and as well as one collaborative European trial (also published with UK data separately). There is overlap between some studies: Collet et al. [40, 48] presented the same sample with different outcomes. Simons et al. [42] present the UK subgroup of the Macht et al. [29] study and personal communication with the authors confirmed overlap between the Li et al. [19] and Horne et al. [20] samples. Nineteen studies were RCTs [21-28, 30-35, 37, 38, 40, $48,49]$, one using a crossover design; five were nonrandomised controlled trials $[36,39,43,45,47]$ and the other 12 studies $[19,20,29,41,42,44,46,50-54]$ were within subject designs with pre- and post-intervention comparisons.

\section{Characteristics of participants}

Seven studies included both people with Parkinson's disease and their relatives or caregivers [23, 33, 36, 41, 43, $47,55]$. Twelve studies included age as an inclusion criterion. The mean age of participants ranged from 52 years [46] to 79 years [50]. Inclusion criteria specified Hoehn and Yahr (H\&Y) stage [56] in half of the studies with the majority restricting to mild-moderate disease and only four studies included H\&Y stage IV. Exclusion criteria based on cognition were used by 23 studies; some used a diagnosis of dementia or cognitive impairment, some used a subjective functional interpretation (e.g. cognitive impairment that precludes consent or prohibits participation), and others used cognitive assessment measures, of varying thresholds. Six studies exclusively recruited people with Parkinson's disease with specific symptoms targeted by the intervention: Depression [22, 25]; anxiety
[38]; drooling [24]; posture [44]; and communication difficulties [50]. One study specifically recruited those with another medical condition to analyze of the impact of comorbidity [31].

\section{Nature of the self-management interventions}

Most interventions were specific to Parkinson's disease, although two studies examined a more general, established self-management programme, the Stanford Chronic Disease Self-Management Programme (CDSMP), in a sample of people with Parkinson's disease, and one speech therapy intervention was not conditionspecific but tailored to the individual and included a Parkinson's disease subgroup. The interventions studied were varied but can broadly be divided into five categories as described in Table 3, with topics of content from self-management education and training programmes detailed in Table 4. The interventions are further detailed using the TIDier checklist [57] in Additional file 2.

\section{Mode of delivery}

A variety of communication and healthcare technologies were utilised for delivery, reducing contact time with professionals. Digital monitoring and cueing devices were employed by four interventions as above, and a further study made us of an electronic pill bottle for collection of medication adherence data [27]. Digital resources demonstrating exercises were used to supplement two interventions: a mindfulness $C D$ [37] and physical exercise DVD [26]. Remotely delivered CBT based interventions were evaluated in two studies [22, 38]. Two studies provided home exercise equipment with game components to engage and motivate participants $[32,51]$.

\section{Duration and intensity of the interventions}

The interventions varied in intensity and duration. One included only a single one-off session [27]; all others involved repeated sessions, typically regular weekly sessions with intensity ranging from $1 \mathrm{~h}$ per week to $3 \mathrm{~h}$ twice a week. Some self-directed interventions involved a recommendation to participate daily. Two studies used fixed intervention points over a longer time period: $3-4$ sessions over 6 months $[34,53]$. Aside from the one-off session intervention, the lengths ranged from 2 weeks to 6 months.

\section{Study outcomes}

Half of the studies assessed outcome immediately following the intervention and the other half also included a delayed follow-up to examine sustainability of outcomes. Whilst frequent, the QoL measures were often not the primary outcomes and as such, the RCTs were not necessarily powered specifically to detect a change on this 
Table 3 Categories of Interventions

\begin{tabular}{|c|c|c|}
\hline Category & Details & $\begin{array}{l}\text { Number } \\
\text { of } \\
\text { Studies }\end{array}$ \\
\hline (i) Self-management education and training programmes & $\begin{array}{l}\text { All but one were group-based, ranging from } 4 \text { to } 20 \text { participants } \\
\text { per group for those that specified, delivered by trained staff, and } \\
\text { provided paper hand-outs. The other was delivered remotely, via } \\
\text { mail, tailoring according to participant questionnaire responses [33]. } \\
\text { Content topics are described in Table 3. }\end{array}$ & 13 \\
\hline (ii) Self-management training combined with other therapies. & $\begin{array}{l}\text { The other therapies were: } \\
\text { - Multidisciplinary rehabilitation } \\
\text { - Physical exercise } \\
\text { - Cognitive Behaviour Therapy (CBT) } \\
\text { - Multidisciplinary care co-ordination } \\
\text { - Mindfulness } \\
\text { These mostly followed a group session model too, though when } \\
\text { combined with CBT and care-coordination this was done on an } \\
\text { individual basis. One study compared a group-based delivery of } \\
\text { exercise and self-management training with a self-guided equivalent } \\
\text { programme [24]. }\end{array}$ & 7 \\
\hline (iii) Specific self-management skill of self-monitoring & $\begin{array}{l}\text { These made use of digital devices to self-monitor: } \\
\text { - Symptoms and medication } \\
\text { - Posture } \\
\text { - Physical activity } \\
\text { These were performed on an individual basis, though the physical } \\
\text { activity monitoring also included an online peer support group. }\end{array}$ & 3 \\
\hline $\begin{array}{l}\text { (iv) Self-management of individual clinical features of Parkin- } \\
\text { son's }\end{array}$ & $\begin{array}{l}\text { Clinical features targeted: } \\
\text { - Anxiety, using CBT - individual } \\
\text { - Drooling, via a digital cueing device - individual } \\
\text { - Communication difficulties through Speech \& Language Therapy } \\
\text { (SLT) - small groups, based on diagnosis. }\end{array}$ & 3 \\
\hline $\begin{array}{l}\text { (v) Self-management of specific treatments, i.e. self-guided treat- } \\
\text { ment programmes }\end{array}$ & $\begin{array}{l}\text { These included: } \\
\text { - Medication } \\
\text { - Physical exercise } \\
\text { - Handwriting exercises } \\
\text { - Acupressure \& conduction exercise } \\
\text { For these the individual was either taught or instructed on how } \\
\text { to self-pursue the treatment. These studies either evaluated the } \\
\text { self-guided delivery of a treatment, or compared different delivery } \\
\text { methods for established interventions. }\end{array}$ & 10 \\
\hline
\end{tabular}

measure. The majority of studies used primary outcome measures related to the specific clinical issue targeted by the intervention. Participant evaluation of the intervention was included in 15 studies, discussed in Additional file 4 .

\section{Effect of interventions}

\section{Self-management education and training programmes}

Three RCTs evaluated group Parkinson's disease-specific education programmes that include in-person training in self-management skills. None showed significant improvements in QoL compared to controls. One [23], reported significantly increased psychosocial adjustment in caregivers in the intervention compared to the usual care control group. There was also a trend towards improvement in QoL for participants with Parkinson's disease for the intervention group and deterioration in the control group, but after Bonferroni correction the difference was not statistically significant. Another shorter intervention (3 sessions) [28], showed no significant effect pre- versus post intervention or compared to a control group who received information only. The third found improvement in PDQ-39 scores, psychosocial adjustment and caregiver 'coping', in both intervention and control groups, with the latter receiving multidisciplinary education without the psychological components, but no significant group effect [33]. Another RCT investigated a related intervention: an individualised education-based intervention, delivered to the participant by mail [34]. This showed improvements in the intervention compared to the usual care control arm in the Parkinson's Questionnaire outcome measure which included functional items modified from the UPRDS. Score for the self-efficacy subdomain of their custom QoL questionnaire were also significantly better in the intervention than control group at follow-up, but not the total score, and there was no baseline measurement of this questionnaire to evaluate change following the intervention. 
Table 4 Content Topics in the Self-Management Education \& Training

\begin{tabular}{|c|c|c|}
\hline \multirow[t]{2}{*}{ Topic } & \multicolumn{2}{|l|}{ Studies } \\
\hline & $\begin{array}{l}\text { Self-management education \& training } \\
\text { programmes }(n=13)\end{array}$ & $\begin{array}{l}\text { Combined with } \\
\text { other Therapies } \\
(n=6)\end{array}$ \\
\hline $\begin{array}{l}\text { Parkinson's disease } \\
\text { Typically information about the disease and its management. }\end{array}$ & $\begin{array}{l}11 \text { studies } \\
{[23,28,29,33,34,42,43,45-47,54]}\end{array}$ & $\begin{array}{l}4 \text { studies } \\
{[19,20,37,55]}\end{array}$ \\
\hline $\begin{array}{l}\text { Communication and/or Relationships } \\
\text { Social or professional }\end{array}$ & $\begin{array}{l}11 \text { studies } \\
{[23,28,29,33,36,41-43,45-47]}\end{array}$ & $\begin{array}{l}4 \text { studies } \\
{[19,20,25,35]}\end{array}$ \\
\hline $\begin{array}{l}\text { Psychological Aspects } \\
\text { Stress, anxiety, depression; } \\
\text { Coping strategies; future concerns }\end{array}$ & $\begin{array}{l}8 \text { studies } \\
{[23,29,33,42,45-47,54]}\end{array}$ & $\begin{array}{l}6 \text { studies } \\
{[19,20,22,25,35,37]}\end{array}$ \\
\hline $\begin{array}{l}\text { Utilising Self-Management Skills }{ }^{\mathbf{a}} \\
\text { Including self-monitoring, problem solving, information seeking, decision } \\
\text { making, maintaining changes, goal setting, action plans. }\end{array}$ & $\begin{array}{l}10 \text { studies } \\
{[23,28,29,36,41-43,46,47,54]}\end{array}$ & $\begin{array}{l}3 \text { studies } \\
{[22,25,35]}\end{array}$ \\
\hline $\begin{array}{l}\text { Lifestyle } \\
\text { Healthy lifestyle, exercise, diet, sleep hygiene; enriching activities }\end{array}$ & $\begin{array}{l}9 \text { studies } \\
{[23,28,29,33,34,42,45-47]}\end{array}$ & $\begin{array}{l}5 \text { studies } \\
{[19,20,22,25,37]}\end{array}$ \\
\hline Social and/or Financial Support & $\begin{array}{l}8 \text { studies } \\
{[23,28,29,33,42,45,46,54]}\end{array}$ & $\begin{array}{l}2 \text { studies } \\
{[25,37]}\end{array}$ \\
\hline $\begin{array}{l}\text { Function } \\
\text { Activities of daily living, mobility, specific exercises }\end{array}$ & $\begin{array}{l}5 \text { studies } \\
{[28,34,45,46,54]}\end{array}$ & $\begin{array}{l}4 \text { studies } \\
{[19,20,25,35]}\end{array}$ \\
\hline
\end{tabular}

${ }^{a}$ Note all interventions incorporated self-management skills, those listed here included specific education sessions on them

Three non-randomised controlled trials evaluated similar self-management interventions [43, 45, 47], one of which showed improvements pre-post intervention in QoL and health status (PDQ-8, EQ5D and LiSat-11) [47], not replicated in the other two. Another of these did show a small improvement in caregiver strain in the intervention arm compared to control, but alongside greater deterioration in physical health for the people with Parkinson's disease and greater deterioration in caregiver depressive symptoms in the intervention versus control [43]. It also showed improvements in self-management outcomes that were greater in the intervention arm than control, particularly for caregivers.

Another non-randomised controlled trial evaluated the well-established Stanford CDSMP (not Parkinson's disease -specific), but did not present the QoL results, instead using it as a factor in analysis [36]. The primary outcome was a social support measure which did not significantly change.

A further five studies, of which two overlap in samples, were non-controlled trials using pre-post intervention evaluation [29, 41, 42, 46, 54] . Regarding our outcomes of interest, one demonstrated significant improvements in psychosocial adjustment for the participants with Parkinson's disease [29] and another showed improvements in activities of daily living at the delayed followup assessment ( 17 weeks). Another, that did not include our outcomes of interest did show improvements in selfmanagement outcomes and a physical measure of axial rotation [46]. No other positive findings were reported.

\section{Self-management training combined with other therapies}

Two of the four RCTs in this category present positive findings. A larger RCT $(n=117)$ evaluated MDT rehabilitation combined with self-management training, that focused predominantly on day-to-day tasks. They report significantly improved QoL (PDQ-39, primary outcome) compared to controls who received no rehabilitation [35]. Findings were sustained, albeit lessened over time (6-month follow-up). Additionally an RCT evaluated an intervention delivering cognitive behaviour therapy (CBT) with self-management training by telephone. This showed significant improvements in both symptoms of depression, the primary outcome that it was targeted to address, and QoL (indicated by the Mental Health composite Score of the SF-36), compared to those in the control arm [22].

Another RCT evaluated a group-delivered course that combined mindfulness and self-management training. In pre-post intervention comparison for all participants (intervention and waitlist controls) after 6 month, significant improvement in the 'ADL' domain of the QoL measure was seen [37]. However, improvements in QoL were not significant compared to waitlist controls. The fourth randomized trial evaluated selfmanagement training combined with exercise for people with Parkinson's disease and depression, comparing group based and self-guided delivery, but without a no-intervention control [25]. No difference was found between the groups. When data was pooled across both arms, there was a significant improvement in 
depressive symptoms pre/post intervention. QoL measures were not used.

Two non-controlled studies, with some sample overlap between them, evaluated a programme that combined multidisciplinary education with physical exercise, emphasizing self-management. They demonstrated improved mobility and balance outcomes, as well as improved QoL at short-term follow-up. The QoL improvement was not sustained at not long-term follow-up 12 months later [20], though exercise behavior was [19]. A non-controlled study of an integrated care model, incorporating multidisciplinary professionals and emphasizing self-management, reported significant improvements in QoL at 6 months, but not 3 months [53].

\section{Self-monitoring interventions}

An RCT evaluating a 'Parkinson's tracker app', did not show statistically significant improvements in QoL compared to the control. There was significant improvements compared to controls in the primary outcome of selfreported medication adherence [30] and improved perceived quality of Parkinson's disease care.

The other trials were small, non-controlled feasibility studies of narrow clinical focus: A study of a physical activity tracker plus online support group for older people with Parkinson's disease [52] and a study of an 'ambulatory posture detection device' [44]. The former did not show any significant improvements, including QoL or function. The latter showed significant improvement in trunk angle as a measure of stoop (primary outcome) but it did not use QoL or function measures.

\section{Self-management of individual clinical features of Parkinson's disease}

One RCT evaluated a CBT-based self-help resource with telephone support against information only with one telephone call [38]. Pre-post intervention comparison showed a significant reduction in worry and intolerance of uncertainty, which the intervention was targeted to address, whilst worry significantly increased in the control group, but the between-group difference was not statistically significant. There was no significant difference pre-post intervention or group difference for QoL (PDQ-39).

The other studies in this category were small and did not evaluate QoL or wellbeing outcomes, but rather measures of the targeted feature. One was a small pilot RCT (cross-over) $(n=27)$ evaluating a digital cueing device for drooling. The validated measures of drooling symptoms showed no significant improvement prepost or between groups, but the improvement in 'overall severity' domain of a self-reported symptom measure using a visual analogue scale was significantly better than the control. The other was a pre-post intervention evaluation of speech and language therapy for nursing home residents with communication difficulties [50]. One of the four participants with Parkinson's disease was seen to improve on a communication effectiveness measure and two on a knowledge measure, but not the other participants.

\section{Self-guided treatment programmes}

A variety of treatments were studied: exercise; medication management; and acupressure \& conduction therapy.

An RCT evaluated a physiotherapist-supported, selfguided exercise programme compared to a self-guided handwriting exercise control group [40, 48]. The exercise group showed significant improvements in QoL and wellbeing (EQ5D-5L and SF-36), compared to the handwriting control, though the effect sizes were small. Significant improvements in the exercise group were seen in the MDS-UPDRS motor scores (moderate effect size) [40] and handwriting scores in the handwriting group (small effect size) [48]. An RCT evaluating a home based aerobic exercise programme demonstrated significantly improved motor scores, the primary outcome measure, compared to a control group undertaking stretching exercises [32]. Improvements in QoL (PDQ-39) were not significantly different between the groups. A trial of an exercise intervention comparing different modes of delivery, discussed in 4.10 below, showed improvements in QoL (PDQLQ) but had no control group [21]. A pre-post intervention comparison in a pilot study of home-based balance training did not use QoL or wellbeing outcomes. It showed significantly improved mobility, but not balance [51].

An RCT investigated a single educational session regarding pharmacology of Parkinson's disease treatment, delivered one-to-one to the participants in the outpatient setting by a clinician [27], aiming to improve medication adherence. No significant changes were seen for QoL or function measures. Significant improvements were seen in the primary outcome of medication adherence, measured using electronic pill bottles, compared to the control arm.

A pilot RCT, which evaluated self-administered acupressure and conduction therapy, did not find significant improvements in QoL (PDQ-39, Chinese version), the primary outcome measure, compared to the control arm [49]. This study had a high attrition rate of $50 \%$ in the control arm (24\% in intervention arm).

\section{Comparisons of delivery methods}

The one study using QoL as a primary outcome measure, significantly favoured the physiotherapy-supervised exercise group over the self-guided exercise group [21]. 
Similarly, improvements in health status and UPDRS parts I-III (separately and total) were significantly greater in the physiotherapist-supervised group. Both groups had also received individualised education about Parkinson's disease and the exercise programme.

The other studies, using motor, mobility or physical performance outcomes, did not show significant differences between therapist-led and self-guided exercise groups [26, 31, 39]. Only one of these included QoL and function measures. There were improvements in physical performance and ADLs in the individual physiotherapy arm but not the self-guided or group therapy arms, and improvements in QoL in the self-guided and group therapy arms but not the individual physiotherapy arm [31], the group differences were not significant.

\section{Components of interventions}

Analysing the interventions using the PRISMS Self-Management taxonomy, it is clear that most interventions are complex, multi-component, targeting different aspects of self-management. Table 5 illustrates the self-management components of the interventions that were associated with improvements in QoL, wellbeing or function, either compared to controls (4 studies - indicated by *) or pre-post intervention evaluation (9 studies). Table 6 shows the components of the interventions that did not demonstrate improvements in these outcomes. Interventions that were reported to be effective included different combinations of components. However, components that appear more frequently in interventions resulting in improvement than in those that do not are: information about resources; training or rehearsing psychological strategies; social support; and lifestyle advice and support.

Intervention evaluations by participants (questionnaires and/or interviews) do not identify clinically effective components but offer insight to well-received components. One report identified the topic of 'stress management' as the most highly rated session. Six evaluations specifically highlighted social or peer support aspects, such as sharing of experiences, as being particularly beneficial $[25,29,36,37,41,59]$. Evaluation of the physical activity tracker with online support group identified peer support as a mechanism for behaviour change [52].

One of the four positive RCTs included caregiver participation in the intervention, finding positive impacts on caregiver outcomes. Four of the 10 studies showing improvements in QoL or function following the intervention for the person with Parkinson's disease, compared to two of the 10 that did not find such improvement, included caregivers in the intervention.

\section{Analysis}

The heterogeneity of study designs, interventions and outcome measures allowed for pooling of data from only four category (i) studies. Meta-analysis, as illustrated in Fig. 2, shows the pooled data for QoL outcomes for four $\mathrm{RCTs}$ of self-management education and training programmes. The risk of bias in these studies ranged from low to high. The three group-based programmes all used the PDQ39 outcome measure, although only one provided data for change in scores. The fourth study, of an individual mail-out education intervention, used a QoL custom questionnaire at follow-up only. Pooling the results, the standardised mean difference (Hedges g) of $-0.17(-0.56,0.21)$ suggests a possible small benefit from interventions, but there is no statistical evidence to confirm this $(p=0.38)$. The $\mathrm{I}^{2}$ value of $68 \%$ suggests a relatively high level of heterogeneity between the studies. By the GRADE approach, the certainty of the evidence is deemed "very low" (for the Evidence Profile, see Additional file 5).

Three non-randomised trials of category (i) interventions with similar outcomes were not suitable for inclusion due to baseline imbalance in scores, which was adjusted for in the papers but did not provide insufficient information to adjust for in meta-analysis. Interventions in other categories could not be synthesised quantitatively as they used different therapies and targeted different clinical aspects of Parkinson's disease.

\section{Discussion}

\section{Effectiveness of interventions}

Overall, there is a paucity of studies of high quality randomised controlled trials of self-management in Parkinson's disease. Most of the identified studies are small and of low quality. The variable applications of self-management concepts confer heterogeneity of study aims, content and outcome measures. This is consistent with findings of the previous review of self-management interventions in Parkinson's disease [9], although even more apparent in our review given the broader definition used.

Meta-analysis of the few interventions with similar content, target and outcomes did not show a significant effect on QoL compared to the control group for self-management education and training programmes. Amongst the other studies using a control group, significant improvements in QoL were reported with selfmanagement training with CBT [22], MDT rehabilitation [35], and self-guided exercise [40]. However, across the whole selection of controlled studies identified, this was not a consistent finding. Many studies did not use QoL, wellbeing or functional outcomes as primary outcomes which may account for some of the negative results. One 


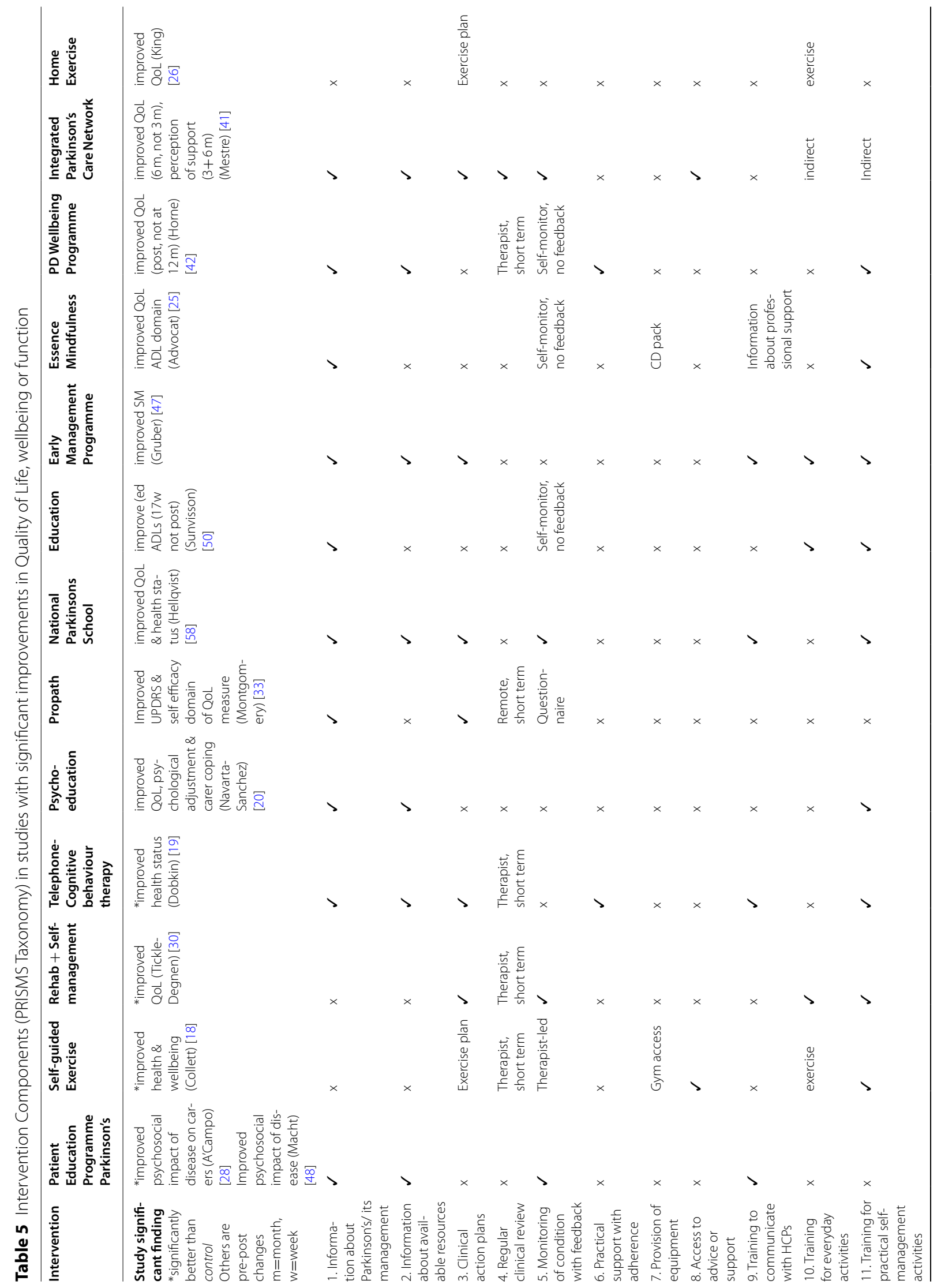




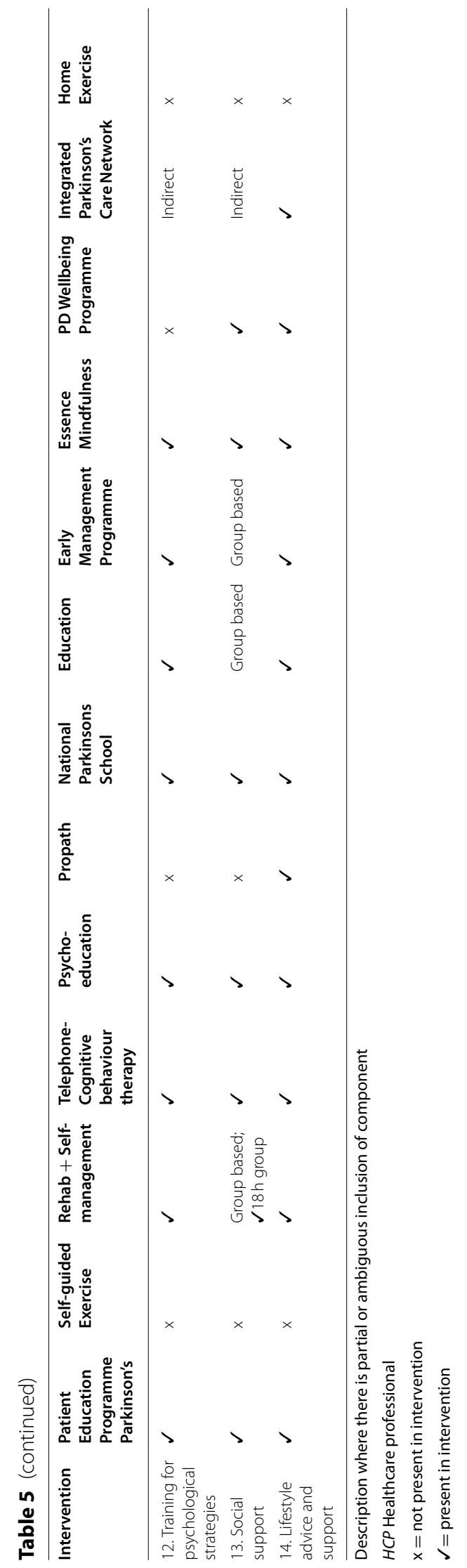


Pigott et al. BMC Geriatrics

(2022) 22:45

Page 24 of 29

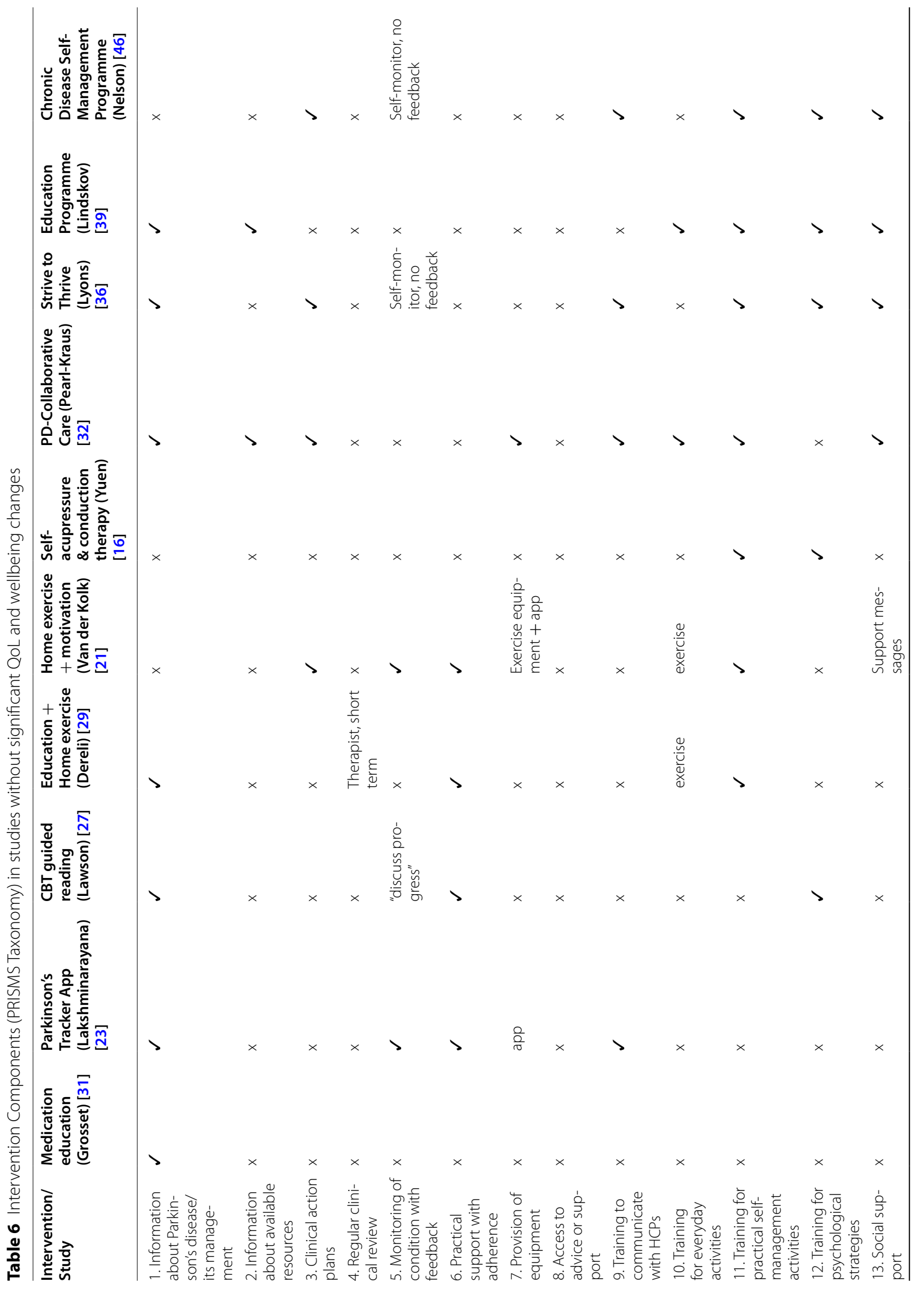




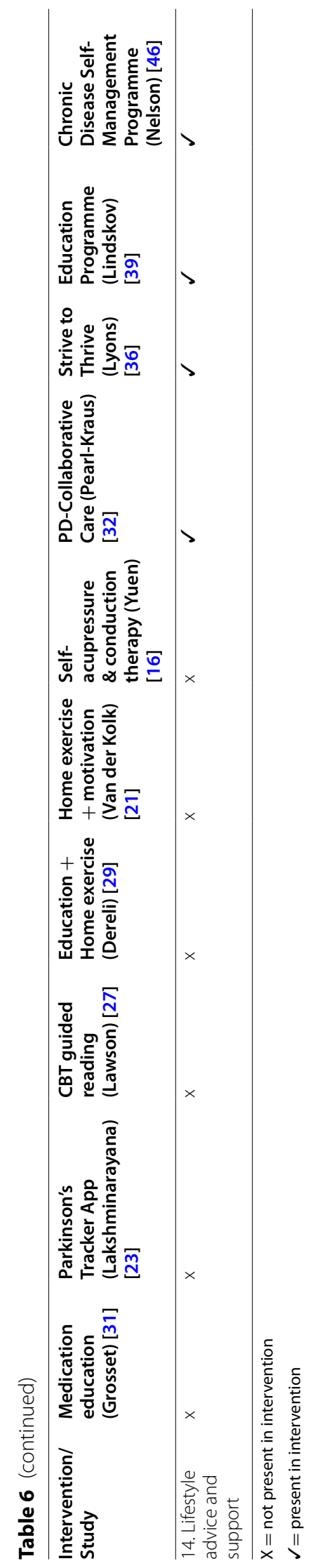




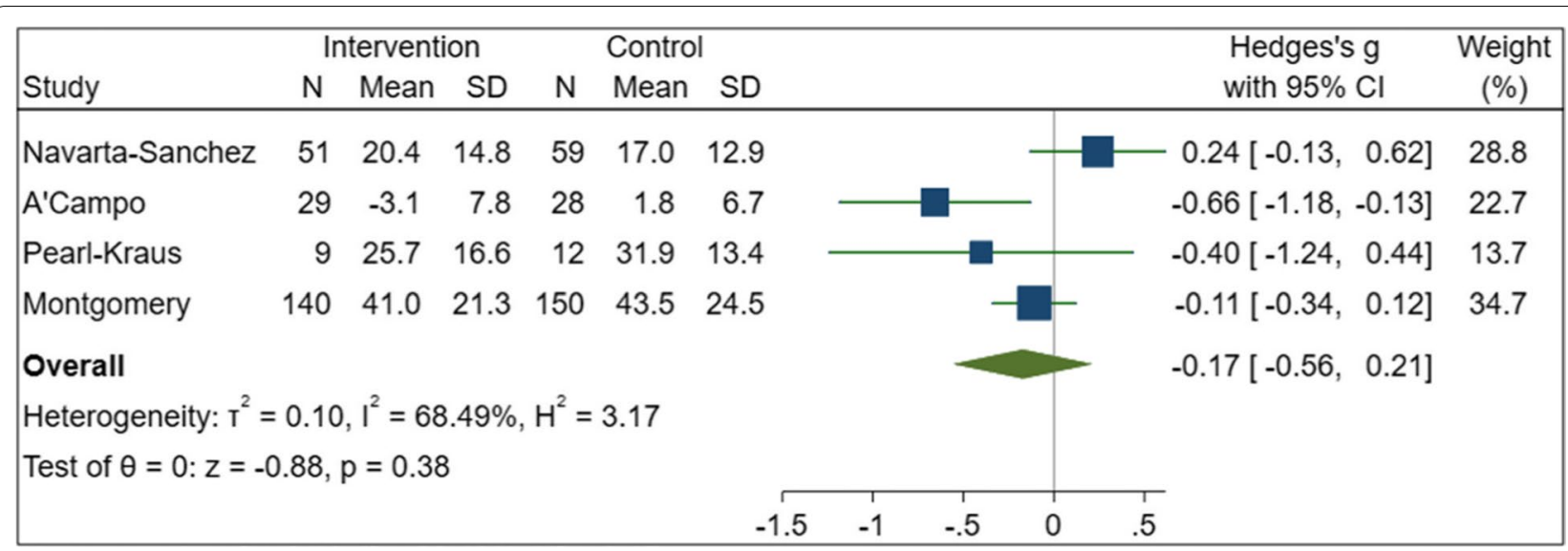

Fig. 2 Forest plot for four RCTs evaluating group-based self-management education and training programmes effect on QoL against standard care

study did show significant improvements in perceived psychosocial impact of disease for caregivers [23].

Comparisons of baseline to post intervention assessments did suggest that self-management interventions and self-guided treatments may have positive effects on these outcomes, including for some group-based education and self-management programmes [29, 46, 47, 54]; a remotely delivered individual education and self-management programme [34]; interventions combining education and self-management training with exercise [20,31] or mindfulness [37], and an integrated care model combining multidisciplinary professional input, education and self-management training [53]. Further controlled studies on these interventions are however required.

\section{Intervention components}

Limited conclusions about specific intervention components can be drawn due to the low quality and heterogeneity of evidence. There is a suggestion that inclusion of a greater number of components, addressing a range of aspects of self-management, may be beneficial, which is consistent with past research for self-management in long term conditions [7]. The majority of interventions incorporated information about Parkinson's disease and its management, but not all found significant improvement in outcome. Information alone does therefore not appear sufficient to improve QoL, in keeping with research in other conditions [7]. Components more common of interventions showing improvements (typically pre-post rather than compared to control), but less common in interventions not showing improvement, were: information about resources; training or rehearsing psychological strategies; social support; and lifestyle advice and support. Whilst not a specific component of selfmanagement, exercise was emphasised in many of these interventions, which is well recognised to be important in Parkinson's disease [60]. There is notable overlap between these components and those identified as important through our previous synthesis of qualitative literature on self-management in Parkinson's disease [14]: (1) medication management, (2) physical exercise, (3) selfmonitoring, (4) psychological strategies, (5) maintaining independence, (6) social engagement, and (7) knowledge and information.

\section{Other intervention variables}

The intensity and duration of interventions may play a role in effectiveness, which in clinical practice would need to be balanced with cost and resource considerations. There is no predictable association between these factors alone and the effect of interventions discernible in this review. A study that appears to have similar content and components to those showing pre-post improvements, but did not itself find significant improvements, was notably shorter than average, with only 3 sessions [28].

Two of the four positive RCTs, and seven of the 10 studies conferring pre-post intervention improvements were group-based programmes. Others used remote methods of delivery (two self-guided following instructions, one telephone therapy, and one postal guidance), supporting this possibility for future interventions. Other than self-monitoring devices, one of which incorporated information about Parkinson's disease from charities onto an app, no study used a digital package to support self-management at home. Past research in long term conditions more generally has not elucidated a particular education delivery method as being more favourable than others [7].

Previous research found support of family to be associated with better self-efficacy which was predictive 
of better self-management in Parkinson's disease [61]. Involvement of caregivers within self-management interventions has been postulated as a mediator of effectiveness [9]. Whilst our findings suggest a trend to support this, the evidence is not conclusive.

Most attrition in the studies was labelled "lost to follow-up" or "medical reasons", without detailed reasons. Some reported practical and logistical reasons, such as transport, time and cost. Two studies report individual drop-outs based on the group nature of the intervention - one discouraged by seeing another participant's condition [41], and one put off by the expectation to talk with others about their condition [28]. These factors may influence design of future interventions.

\section{Strengths and limitations}

The main strength of this review is the robust and reproducible methodology, adhering to PRISMA guidelines, and the broad inclusion criteria to provide a comprehensive review of studies in the field. The methodology involved multiple databases, extensive search terms, and two independent reviewers.

Self-management is an inherently broad concept, further evidenced by the diversity of interventions described in this review. Other interventions may incorporate self-management aspects, for example singing or dance interventions, but without explicit self-management conceptualisation. Thus, some studies may not have been identified due to lack of attribution or recognition of self-management concepts. Use of resources like the TIDier checklist to describe interventions, and the PRISMS Taxonomy of Self-Management will help alleviate this issue in the future. Furthermore, most studies lacked detailed description of the control arm, particularly regarding 'usual care'. Since this may include some self-management components, such as 'provision of equipment', this limits the interpretation of active intervention components and their effectiveness.

Non-English language articles were excluded which excluded 3 potentially relevant studies: one of a self-management programme in Parkinson's disease [58] (Korean), one of self-catheterisation for urinary symptoms in Parkinson's disease [62] (French), and one of group physiotherapy [63] (German) for which the relevance could not be determined from information available.

Overall, the risk of bias in the studies, in relation to QoL and wellbeing outcomes, was high. The main determinant of this was lack of blinding along with selfreported outcome measures, which are inherent to the nature of these interventions.

\section{Conclusion}

Despite the increasing interest in the topic of self-management in Parkinson's disease, there are insufficient high quality RCTs in this field to draw firm conclusions on the effectiveness of self-management interventions in this population.

No single component was consistently associated with the success of self-management interventions to improve QoL, wellbeing or function. Whilst the previously recognised key components of education, goal setting, and problem solving were common, they did not distinguish effectiveness. Components that were more common in interventions associated with improvements in these outcomes, albeit often not compared to controls, were: information about resources; training or rehearsing psychological strategies; social support; and lifestyle advice and support. Focused interventions relating to specific self-management skills or self-management of specific clinical features or treatments do show promise for improving the targeted feature, but the significance of this for the individual remains to be shown.

More high quality RCTs are needed to determine the clinical effectiveness of self-management in PD, with suitable carefully chosen clinically relevant outcomes.

\section{Supplementary Information}

The online version contains supplementary material available at https://doi. org/10.1186/s12877-021-02656-2.

Additional file 1. Search Terms.

Additional file 2. Intervention Details - TIDieR [54].

Additional file 3. Risk of Bias Assessment.

Additional file 4. Results of Intervention Evaluations.

Additional file 5. GRADE Approach: Evidence Profile for Meta-analysis.

\section{Acknowledgements}

This work was undertaken on behalf of the PD-Care Study group: Catherine Atkinson (Homerton University Hospital NHS Foundation Trust), Richard Brown (King's College London), Kallol Ray Chaudhuri (King's College Hospital NHS Foundation Trust), Nathan Davies (University College London), Daniel Davis (University College London), Benjamin Gardner (King's College London), Rachael Hunter (University College London), Jill Manthorpe (King's College London), Beverley Maydon (Royal Free London NHS Foundation Trust), Elizabeth Murray (University College London), Joy Read (University College London).

\section{Authors' contributions}

All authors contributed to the design of the review. JP and EK conducted the searches, screening and article review, under the supervision of AS and KW. GA led the meta-analysis. All authors made significant contribution to the writing of the manuscript, have read and approved the final manuscript.

\section{Funding}

This report is independent research funded by the National Institute for Health Research (NIHR) (Programme Grants for Applied Research, Personalised care for people with Parkinson's Disease: PD-Care, RP-PG-1016-20001). The views expressed in this publication are those of the authors and not necessarily 
those of the NHS, the National Institute for Health Research or the Department of Health.

\section{Availability of data and materials}

The search strategies used in this systematic review are available in the supplement. All data used in this systematic review are from previously reported studies and datasets, which have been cited.

\section{Declarations}

\section{Ethics approval and consent to participate}

Not applicable.

\section{Consent for publication}

Not applicable.

\section{Competing interests}

The authors declare that they have no competing interests.

\begin{abstract}
Author details
${ }^{1}$ Queen Square Institute of Neurology, University College London, London, UK. ${ }^{2}$ South London \& Maudsley NHS Foundation Trust, London, UK. ${ }^{3}$ Department of Statistical Science, University College London, London, UK. ${ }^{4}$ Centre for Ageing Population Studies, Research Department of Primary Care and Population Health, University College London, London, UK. ${ }^{5}$ UCL Institute of Neurology, Royal Free Campus, University College London, London NW3 2PF, UK.
\end{abstract}

Received: 6 May 2021 Accepted: 23 November 2021 Published online: 11 January 2022

\section{References}

1. UK P. The incidence and prevalence of Parkinson's in the UK results from the clinical practice research datalink summary report. 2018.

2. Pringsheim T, Jette N, Frolkis A, Steeves TDL. The prevalence of Parkinson's disease: a systematic review and meta-analysis. Mov Disord. 2014;29:1583-90.

3. Kuhlman GD, Flanigan JL, Sperling SA, Barrett MJ. Predictors of healthrelated quality of life in Parkinson's disease. Park Relat Disord. 2019;65:8690. https://doi.org/10.1016/j.parkreldis.2019.05.009.

4. Panagioti M, Richardson G, Small N, Murray E, Rogers A, Kennedy A, et al. Self-management support interventions to reduce health care utilisation without compromising outcomes: a systematic review and meta-analysis. BMC Health Serv Res. 2014;14:356.

5. Lorig KR, Holman HR, Med AB. Self-management education : history, definition, outcomes, and mechanisms. Ann Behav Med. 2003;26:1-7.

6. Pearce G, Parke HL, Pinnock H, Epiphaniou E, Bourne CLA, Sheikh A, et al. The PRISMS taxonomy of self-management support: derivation of a novel taxonomy and initial testing of its utility. J Heal Serv Res Policy. 2016;21:73-82.

7. Taylor SJ, Pinnock H, Epiphaniou E, Pearce G, Parke HL, Schwappach A, et al. A rapid synthesis of the evidence on interventions supporting selfmanagement for people with long-term conditions: PRISMS - practical systematic Revlew of self-management support for long-term conditions. Heal Serv Deliv Res. 2014;2:1-580.

8. NICE. Parkinson's disease in adults. 2019; 2017.

9. Kessler D, Liddy C. Self-management support programs for persons with Parkinson's disease: an integrative review. Patient Educ Couns. 2017;100:1787-95. https://doi.org/10.1016/j.pec.2017.04.011.

10. Coulter A. Patient-focused interventions: a review of the evidence; 2006 p. 1-277. http://www.health.org.uk/publications/patient-focused-inter ventions/

11. Moher D, Liberati A, Tetzlaff J, Altman DG, Altman D, Antes G, et al. Preferred reporting items for systematic reviews and meta-analyses: the PRISMA statement. PLoS Med. 2009;6(7):e1000097.

12. Page MJ, MCKenzie JE, Bossuyt PM, Boutron I, Hoffmann TC, Mulrow CD, et al. The PRISMA 2020 statement: an updated guideline for reporting systematic reviews. BMJ. 2021;372:n71.
13. Hughes AJ, Daniel SE, Kilford L, Lees AJ. Accuracy of clinical diagnosis of idiopathic Parkinson's disease: a clinico-pathological study of 100 cases. J Neurol Neurosurg Psychiatry. 1992;55:181-4.

14. Tuijt R, Tan A, Armstrong M, Pigott J, Read J, Davies N, et al. Selfmanagement components as experienced by people with Parkinson's disease and their carers: a systematic review and synthesis of the qualitative literature. Parkinsons Dis. 2020;8857385.

15. Barlow J. How to use education as an intervention in osteoarthritis. Best Pract Res Clin Rheumatol. 2001;15:545-58.

16. Sterne JAC, Savović J, Page MJ, Elbers RG, Blencowe NS, Boutron I, et al. RoB 2: a revised tool for assessing risk of bias in randomised trials. BMJ. 2019;366:1-8.

17. Sterne JAC, Savović J, Page MJ, Elbers RG, Blencowe NS, Boutron I, et al. Cochrane; ROBINS-I_detailed_guidance. BMJ. 2019;366(October):1-53. https://doi.org/10.1136/bmj.14898.

18. Higgins JPT, Thomas J, Chandler J, Cumpston M, Li T, Page MJ WV. Cochrane handbook for systematic reviews of interventions. Version 6. Cochrane, 2021.; 2021. www.training.cochrane.org/handbook.

19. Li G, Horne J, Paul SS. Health behaviors a year after an early intervention exercise and education program for people with Parkinson's disease. Neurodegener. Dis Manag. 2020;(October); 11(1):65-75. https:// doi.org/10.2217/nmt-2020-0031.

20. Horne JT, Soh D, Cordato DJ, Campbell ML, Schwartz RS. Functional outcomes of an integrated Parkinson's disease wellbeing program. Australas J Ageing. 2020;39:e94-102.

21. Dereli EE, Yaliman A. Comparison of the effects of a physiotherapistsupervised exercise programme and a self-supervised exercise programme on quality of life in patients with Parkinsonĝ $€^{\mathrm{TM}} \mathrm{s}$ disease. Clin Rehabil. 2010;24:352-62.

22. Dobkin RD, Mann SL, Gara MA, Interian A, Rodriguez KM, Menza M. Telephone-based cognitive behavioral therapy for depression in Parkinson disease: a randomized controlled trial. Neurology. 2020;94:E1764-73.

23. A'Campo LEl, Wekking EM, Spliethoff-Kamminga NGA, Le Cessie S, Roos RAC. The benefits of a standardized patient education program for patients with Parkinson's disease and their caregivers. Park Relat Disord. 2010;16:89-95. https://doi.org/10.1016/j.parkreldis.2009.07.009.

24. McNaney R, Miller N, Vines J, Olivier P, Ladha K, Jackson D, et al. The feasibility and acceptability of using a novel wrist worn cueing device to self-manage drooling problems in people with Parkinson's disease: a pilot study. J Rehabil Assist Technol Eng. 2019;6:205566831985252.

25. Sajatovic M, Ridgel AL, Walter EM, Tatsuoka CM, Colón-Zimmermann K, Ramsey RK, et al. A randomized trial of individual versus group-format exercise and self-management in individuals with Parkinson's disease and comorbid depression. Patient Prefer Adherence. 2017;11:965-73.

26. Atterbury EM, Welman KE. Balance training in individuals with Parkinson's disease: therapist-supervised vs. home-based exercise programme. Gait Posture. 2017;55(September 2016):138-44. https:// doi.org/10.1016/j.gaitpost.2017.04.006.

27. Grosset KA, Grosset DG. Effect of educational intervention on medication timing in Parkinson's disease: a randomized controlled trial. BMC Neurol. 2007;7:1-6.

28. Pearl-Kraus L. Effects of two Parkinson's disease patient education models on disease self-management and quality of life. Diss Abstr Int Sect B Sci Eng. 2007;68:2930 http://ovidsp.ovid.com/ovidweb.cgi?T= $J S \& P A G E=$ reference $\& D=p s y c 5 \& N E W S=N \& A N=2007-99220-037$.

29. Macht M, Gerlich C, Ellgring H, Schradi M, Rusiñol ÀB, Crespo M, et al. Patient education in Parkinson's disease: formative evaluation of a standardized programme in seven European countries. Patient Educ Couns. 2007;65:245-52.

30. Lakshminarayana R, Wang D, Burn D, Chaudhuri K, Hellman B, SMARTPD Investigators I. Using a smartphone based self-management platform to support medication adherence and clinical consultation in Parkinson's disease results from the Smart-PD randomised controlled trial. Value Heal. 2016;19:A700.

31. King LA, Wilhelm J, Chen Y, Blehm R, Nutt J, Chen Z, et al. Effects of group, individual, and home exercise in persons with Parkinson disease: a randomized clinical trial. J Neurol Phys Ther. 2015;39:204-12.

32. van der Kolk NM, de Vries NM, Kessels RPC, Joosten $H$, Zwinderman AH, Post B, et al. Effectiveness of home-based and remotely supervised aerobic exercise in Parkinson's disease: a double-blind, randomised controlled 
trial. Lancet Neurol. 2019;18:998-1008. https://doi.org/10.1016/S14744422(19)30285-6.

33. Navarta-Sánchez MV, Ambrosio L, Portillo MC, Ursúa ME, Senosiain JM, Riverol M. Evaluation of a psychoeducational intervention compared with education in people with Parkinson's disease and their informal caregivers: a quasi-experimental study. J Adv Nurs. 2020;76:2719-32.

34. Montgomery EB, Lieberman A, Singh G, Fries JF. Patient education and health promotion can be effective in Parkinson's disease: a randomized controlled trial. Am J Med. 1994:97:429-35.

35. Tickle-Degnen L, Ellis T, Saint-Hilaire MH, Thomas CA, Wagenaar RC. Selfmanagement rehabilitation and health-related quality of life in Parkinson's disease: a randomized controlled trial. Mov Disord. 2010;25:194-204.

36. Pappa K, Doty T, Taff SD, Kniepmann K, Foster ER. Self-management program participation and social support in Parkinson's disease: mixed methods evaluation. Phys Occup Ther Geriatr. 2017;35:81-98. https://doi. org/10.1080/02703181.2017.1288673.

37. Advocat J, Enticott J, Vandenberg B, Hassed C, Hester J, Russell G. The effects of a mindfulness-based lifestyle program for adults with Parkinson's disease: a mixed methods, wait list controlled randomised control study. BMC Neurol. 2016;16:1-11. https://doi.org/10.1186/ s12883-016-0685-1.

38. Lawson RA, Millar D, Brown RG, Burn DJ. Guided self-help for the management of worry in parkinson's disease: a pilot study. J Parkinsons Dis. 2013:3:61-8.

39. Lun V, Pullan N, Labelle N, Adams C, Suchowersky O. Comparison of the effects of a self-supervised home exercise program with a physiotherapist-supervised exercise program on the motor symptoms of Parkinson's disease. Mov Disord. 2005;20:971-5.

40. Collett J, Franssen M, Meaney A, Wade D, Izadi H, Tims M, et al. Phase II randomised controlled trial of a 6 -month self-managed community exercise programme for people with Parkinson's disease. J Neurol Neurosurg Psychiatry. 2017:88:204-11.

41. Nelson N, Wong D, Lai E. A self-management program for veterans and spouses living with Parkinson's disease. J Nurs Healthc Chronic IIIn. 2011;3:496-503.

42. Simons G, Thompson SBN, Smith Pasqualini MC. An innovative education programme for people with Parkinson's disease and their carers. Park Relat Disord. 2006;12:478-85.

43. Lyons KS, Zajack A, Greer M, Chaimov H, Dieckmann NF, Carter JH. Benefits of a self-management program for the couple living with Parkinson's disease: a pilot study. J Appl Gerontol. 2020.

44. van Wegen EEH, de Goede CJT, Kwakkel G, van Kordelaar J. Sensor assisted self-management in Parkinson's disease: a feasibility study of ambulatory posture detection and feedback to treat stooped posture. Park Relat Disord. 2018;46:S57-61. https://doi.org/10.1016/j.parkreldis. 2017.07.024.

45. Lindskov S, Westergren A, Hagell P. A controlled trial of an educational programme for people with Parkinson's disease. J Clin Nurs. 2007;16:368-76

46. Gruber RA, lluiibregts MP. Self-management programs for people with Parkinson's disease. 2017:24:141-50.

47. Hellqvist C, Berterö C, Dizdar N, Sund-Levander M, Hagell P. Self-management education for persons with Parkinson's disease and their care partners: a quasi-experimental case-control study in clinical practice. Parkinsons Dis. 2020;6920943.

48. Collett J, Franssen M, Winward C, Izadi H, Meaney A, Mahmoud W, et al. A long-term self-managed handwriting intervention for people with Parkinson's disease: results from the control group of a phase II randomized controlled trial. Clin Rehabil. 2017;31:1636-45.

49. Yuen CS, Chua KK, Lau WH, Zhuang ZY, Chow HY, Li M. The effect of conduction exercise and self-acupressure in treatment of Parkinson's disease: a pilot study. Evid-Based Complement Altern Med. 2020;7950131.

50. Jordan FM, Worrall LE, Hickson LMH, Dodd BJ. The evaluation of intervention programmes for communicatively impaired elderly people. Int J Lang Commun Disord. 1993;28:63-85.

51. Esculier JF, Vaudrin J, Bériault P, Gagnon K, Tremblay LE. Home-based balance training programme using Wii fit with balance board for Parkinson's disease: a pilot study. J Rehabil Med. 2012;44:144-50.

52. Hermanns M, Haas BK, Lisk J. Engaging older adults with Parkinson's disease in physical activity using technology: a feasibility study. Gerontol Geriatr Med. 2019;5:233372141984267.
53. Mestre TA, Kessler D, Côté D, Liddy C, Thavorn K, Taljaard M, et al. Pilot evaluation of a pragmatic network for integrated care and self-management in Parkinson's disease. Mov Disord. 2020:1-10.

54. Sunvisson H, Ekman SL, Hjördis Hagberg PT, Lökk J. An education programme for individuals with Parkinson's disease. Scand J Caring Sci. 2001;15:311-7.

55. Kessler D, Hauteclocque J, Grimes D, Mestre T, Côtéd D, Liddy C. Development of the integrated Parkinson's care network (IPCN): using co-design to plan collaborative care for people with Parkinson's disease. Qual Life Res. 2019;28:1355-64. https://doi.org/10.1007/s11136-018-2092-0.

56. Hoehn MM, Yahr MD. Parkinsonism : onset, progression, and mortality; 1967.

57. Hoffmann TC, Glasziou PP, Boutron I, Milne R, Perera R, Moher D, et al. Better reporting of interventions: template for intervention description and replication (TIDieR) checklist and guide. BMJ. 2014;348(March):1-12. https://doi.org/10.1136/bmj.g1687.

58. Sohng K-Y, Moon J-S, Lee K-S, Choi D-W. The development and effects of a self-management program for patients with Parkinson's disease. Taehan Kanho Hakhoe Chi. 2007;37:891-901.

59. UK P, van der Eijk M, Faber MJ, Al Shamma S, Munneke M, Bloem BR, et al. Phase II randomised controlled trial of a 6-month self-managed community exercise programme for people with Parkinson's disease. Park Relat Disord. 2017;3:462-7. https://doi.org/10.1371/journal.pone.0098340.

60. Shu $H$, Yang T, Yu S, Huang $H$, Jiang L, Gu J, et al. Aerobic exercise for Parkinson's disease: a systematic review and meta-analysis of randomized controlled trials. PLoS One. 2014;9(7):e100503.

61. Chenoweth L, Gallagher R, Sheriff JN, Donoghue J, Stein-Parbury J. Factors supporting self-management in Parkinson's disease: implications for nursing practice. Int J Older People Nursing. 2008;3:187-93.

62. Savard E, Declemy A, Coindreau V, Babany F, Chesnel C, Charlanes A, et al. Self-intermittent-catheterization and urinary retentions in parkinsonian syndromes. Prog Urol. 2018;28:987-92. https://doi.org/10.1016/j.purol. 2017.11.004.

63. Bock G. Patient group gymnastics for Morbus Parkinson. Experiences of a self-help group. Krankengymnastik. 1988;40:912-7.

\section{Publisher's Note}

Springer Nature remains neutral with regard to jurisdictional claims in published maps and institutional affiliations.

Ready to submit your research? Choose BMC and benefit from:

- fast, convenient online submission

- thorough peer review by experienced researchers in your field

- rapid publication on acceptance

- support for research data, including large and complex data types

- gold Open Access which fosters wider collaboration and increased citations

- maximum visibility for your research: over $100 \mathrm{M}$ website views per year

At BMC, research is always in progress.

Learn more biomedcentral.com/submissions 